\title{
Evaluating Optical Proxies of Particulate Organic Carbon across the Surface Atlantic Ocean
}

\author{
Rafael Rasse ${ }^{1,2 *}$, Giorgio Dall'Olmo ${ }^{2,3}$, Jason Graff ${ }^{4}$, Toby K. Westberry ${ }^{4}$, \\ Virginie van Dongen-Vogels ${ }^{4}$ and Michael J. Behrenfeld ${ }^{4}$ \\ ${ }^{1}$ Centro de Ciencias Atmosféricas y Biogeoquímica, Instituto Venezolano de Investigaciones Científicas, Caracas, Venezuela, \\ ${ }^{2}$ Plymouth Marine Laboratory, Plymouth, United Kingdom, ${ }^{3}$ National Centre for Earth Observation, Plymouth Marine \\ Laboratory, Plymouth, United Kingdom, ${ }^{4}$ Department of Botany and Plant Pathology, Oregon State University, Corvallis, OR, \\ United States
}

OPEN ACCESS

Edited by:

Katja Fennel,

Dalhousie University, Canada

Reviewed by:

Emmanuel Devred

Fisheries and Oceans Canada,

Canada

Marlon R. Lewis,

Dalhousie University, Canada

${ }^{*}$ Correspondence:

Rafael Rasse

rar@pml.ac.uk; rirasse@gmail.com

Specialty section:

This article was submitted to

Ocean Observation

a section of the journal

Frontiers in Marine Science

Received: 25 May 2017

Accepted: 31 October 2017

Published: 16 November 2017

Citation:

Rasse R, Dall'Olmo G, Graff J, Westberry TK, van Dongen-Vogels V and Behrenfeld MJ (2017) Evaluating Optical Proxies of Particulate Organic

Carbon across the Surface Atlantic

Ocean. Front. Mar. Sci. 4:367.

doi: 10.3389/fmars.2017.00367
Empirical relationships between particulate organic carbon (POC) and inherent optical properties (IOPs) are required for estimating POC from ocean-color remote sensing and autonomous platforms. The main relationships studied are those between POC and particulate attenuation $\left(c_{p}\right)$ and backscattering $\left(b_{b p}\right)$ coefficients. The parameters of these relationships can however differ considerably due to differences in the methodologies applied for measuring IOPs and POC as well as variations in particle characteristics. Therefore, it is important to assess existing relationships and explore new optical proxies of POC. In this study, we evaluated empirical relationships between surface POC and IOPs $\left(c_{p}, b_{b p}\right.$ and the particulate absorption coefficient, $\left.a_{p}\right)$ using an extensive dataset collected during two Atlantic Meridional Transect (AMT 19 and 22) cruises spanning a wide range of oceanographic regimes. IOPs and POC were measured during the two cruises using consistent methodologies. To independently assess the accuracy of the POC-IOPs relationships, we predicted surface POC for AMT-22 using relationships developed based on independent data from AMT-19. We found typical biases in predicting POC ranging between $2-3,4-9$, and $6-13 \%$ for $c_{p}, b_{b p}$, and $a_{p}$, respectively, and typical random uncertainties of $20-30 \%$. We conclude that (1) accurate POC- $c_{p}$ and POC- $b_{b p}$ relationships were obtained due to the consistent methodologies used to estimate POC and IOPs and (2) $a_{p}$ could be considered as an alternative optical proxy for POC in open-ocean waters, only if all physiological variability in the POC:chl ratio could be modeled and used to correct $a_{p}$.

Keywords: particulate organic carbon, inherent optical properties, optical proxies, empirical relationships, Atlantic Ocean

\section{INTRODUCTION}

The biological carbon pump (BCP) is a wide suite of processes through which marine biota remove carbon dioxide from the surface ocean by transporting particulate organic carbon (POC) toward the marine sediments (Volk and Hoffert, 1985). This mechanism contributes to mitigating the earth's climate and affects the main oceanic biogeochemical cycles (Sarmiento and Gruber, 2006). To overcome insufficient spatial and temporal resolution of traditional POC observations, inherent optical properties (IOPs) have been applied as proxies of POC to fully comprehend the key physical and biogeochemical processes that control the BCP (e.g., Bishop et al., 2004; Honjo et al., 2008; Bishop and Wood, 2009). 
Particulate beam attenuation $\left(c_{p}\right)$, backscattering $\left(b_{b p}\right)$, and absorption $\left(a_{p}\right)$ coefficients are IOPs used as optical proxies of POC (Gardner et al., 1993; Stramski et al., 1999; Wozniak et al., 2011). The advantage of applying the IOPs as POC proxies is that these optical properties are retrievable from space and/or by autonomous platforms (Lee et al., 1996; Bishop et al., 2002), which allows prediction of POC-fluxes with a greater temporal and spatial resolution than conventional methods (e.g., Bishop et al., 2004; Bishop and Wood, 2009; Briggs et al., 2011; Estapa et al., 2013; Dall'Olmo and Mork, 2014). One of the main limitations of these methods is that they depend on establishing robust empirical relationships between POC and IOPs.

Numerous studies have been devoted to evaluating the relationship between POC and $c_{p}$ (Loisel and Morel, 1998; Bishop, 1999; Claustre et al., 1999; Mishonov et al., 2003; Gardner et al., 2006) and $b_{b p}$ (Stramski et al., 1999, 2008; Balch et al., 2010; Cetinić et al., 2012). These studies have demonstrated that the derived relationships could differ considerably, which in turn affects the accuracy with which POC is predicted. For example, Gardner et al. (2006) found that the slope of the linear regression between POC and $c_{p}(660)$ varied between 10 and $42 \%$ for different regions of the North Atlantic. More recently, Cetinić et al. (2012) found good linear relationships $\left(R^{2}=\right.$ $0.83)$ between POC and $c_{p}(660)$ and $b_{b p}(550)$ during the North Atlantic Bloom Experiment (NABE), however their relationships are considerably different from previous ones derived for the North Atlantic (Gardner et al., 2006; Balch et al., 2010). These discrepancies may be due to the spatio-temporal variability of phytoplankton-particle assemblages (e.g., particle size, shape, and chemical composition) and the different methodologies applied to measure POC and IOPs (e.g., Boss et al., 2015 and references therein). Thus, it has been suggested that a single global algorithm cannot accurately predict POC (Gardner et al., 2006; Cetinić et al., 2012). Alternatively, robust global relationships may be achieved by exploiting consistent protocols to measure POC and IOPs over a wide range of oceanic conditions and particle assemblages (e.g., Gardner et al., 2006).

Most in-situ studies have focused on the relationship between POC and $b_{b p}$ or $c_{p}$, but there is little information on the utility of $a_{p}$ as a POC proxy (Stramski et al., 2008; Allison et al., 2010a). As with $b_{b p}, a_{p}$ can be derived from satellite ocean color data (e.g., Mitchell et al., 2014). In contrast, $c_{p}$ can only be indirectly estimated from remote sensing, which introduces additional uncertainties on predicted POC. Uncertainties in $b_{b p}$ retrieval from remote sensing still remain and instruments for in-situ measurements of $b_{b p}$ may not be sensitive enough for the open ocean (Twardowski et al., 2007; Dall'Olmo et al., 2012). Thus, POC- $b_{b p}$ relationships may be noisier than POC- $c_{p}$ relationships.

Recently, Allison et al. (2010a,b) found a robust relationship between estimates of in situ POC and blue-green reflectance ratio in the open Southern Ocean. Stramski et al. (2008) developed a similar relationship using data from the Pacific and Atlantic oceans. Allison et al. (2010a) suggested that the variability of the green reflectance ratio is mainly driven by the particle absorption coefficient. Similar results were found in more optically-complex waters between POC and $a_{p}(440)$ (Wozniak et al., 2011). The main goals of the current study are to evaluate the potential factors controlling the accuracy of POCIOPs relationships $\left(b_{b p}\right.$ and $c_{p}$ ) in the surface open ocean and the reliability of $a_{p}$ as POC proxy. To this aim, we develop and compare empirical relationships between surface POC and IOPs $\left(a_{p}, b_{b p}\right.$, and $\left.c_{p}\right)$ using an extensive data set collected during two Atlantic Meridional Transect (AMT) cruises, during which we applied rigorous and consistent protocols to determine IOPs and POC. More specifically, we (1) evaluate the potential sources of uncertainties in POC measurements, and (2) estimate the accuracy of the POC-IOPs relationships developed in this and earlier studies, and discuss the reasons that explain the differences observed between them. From the latter analysis, we highlight that the application of consistent methodologies to measure POC and bio-optical variables is needed to accurately predict POC from POC-IOPs relationships.

\section{MATERIALS AND METHODS}

\section{Description of the Study Area}

Data were collected during AMT-19 (28th October to 22nd November 2009) and AMT-22 (11th October to 20th November 2012). Both cruises spanned the wide range of oceanographic regimes found at latitudes between $\sim 46^{\circ} \mathrm{N}-46^{\circ} \mathrm{S}$ (Figure 1).

\section{Chlorophyll a and Underway Optical Measurements \\ Chlorophyll a}

Chlorophyll-a concentration was estimated optically and by means of high performance liquid chromatography (HPLC). Surface seawater was collected from the ship's clean seawater supply and filtered through pre-combusted $\left(4 \mathrm{~h}\right.$ at $\left.450^{\circ} \mathrm{C}\right) 25$ mm Whatman GF/F filters (1-4 liters, depending on the trophic status of the water masses). Samples were flash-frozen in liquid nitrogen, stored at $-80^{\circ} \mathrm{C}$ and then analyzed using HPLC analysis (Van Heukelem and Thomas, 2001; Mueller et al., 2003). The concentration of total chlorophyll-a was calculated as the sum of the chlorophyll-a, monovinylchl-a, divinyl chlorophyll-a, and chlorophyllide-a (Figure 2).

Optically-derived chlorophyll-a was calculated using the height of the particle absorption peak at $676 \mathrm{~nm}$ following Boss et al. (2007), using data from both AC-9 and AC-s measurements during AMT-19 (Dall'Olmo et al., 2012) and using only AC-s data for AMT-22. Optically-derived chlorophyll-a concentration was validated by comparing it to the HPLC-based total chlorophylla (see Figure 2). Biases of -10 and $+3 \%$ (median relative differences) were found for AMT-19 and AMT-22, respectively. These biases were then removed from the optically-derived chlorophyll concentrations for the rest of the analysis. This biascorrected optically-derived chlorophyll-a is henceforth referred to as $c h l_{o p}$ whereas HPLC-based total chlorophyll-a is referred as chl hplc.

\section{Beam Attenuation and Absorption Coefficients}

Continuous optical measurements were collected on seawater pumped from a nominal depth of $5 \mathrm{~m}$ into the clean underway supply of the RRS James Cook. Bubbles were removed by means 


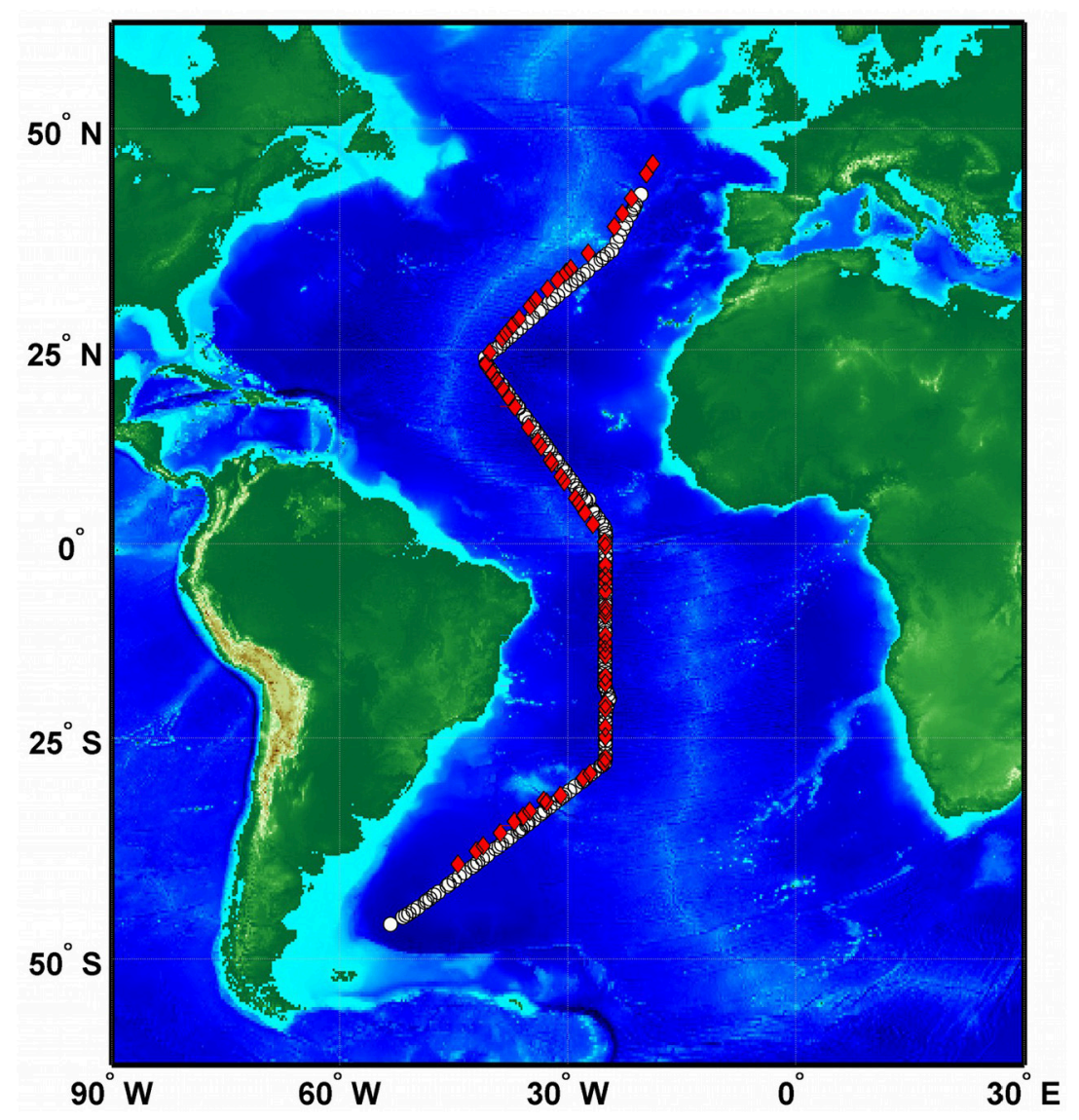

FIGURE 1 | Sampling location for AMT-19 (red diamonds) and AMT-22 (white circles).

of two Vortex debubblers connected in series (model VDB-1G, Stony Brook, NY, USA).

During both cruises particulate beam attenuation coefficients $\left(c_{p}\right)$ were determined by two 25-cm WETLabs C-star transmissometers (526 and $650 \mathrm{~nm}$ ). Hyperspectral $c_{p}$ and particulate absorption coefficients $\left(a_{p}\right)$ were also measured between 400 and $750 \mathrm{~nm}$ by a $25-\mathrm{cm}$ WETLabs spectral absorption and attenuation meter (AC-s, 5-nm spectral sampling, 15-nm band pass). As explained in Dall'Olmo et al. (2012), during AMT-19 the AC-s instrument failed ( year day 298) and was replaced by a WETLabs AC-9 instrument (nine wavelengths between 412 and $715 \mathrm{~nm}, 10-\mathrm{nm}$ band pass).

Particulate absorption and beam-attenuation coefficients, $a_{p}$ and $c_{p}$, were determined by subtracting from the bulk signals those measured on $0.2-\mu \mathrm{m}$ filtered (Cole Parmer nylon cartridge) seawater as previously described (Dall'Olmo et al., 2009, 2012; Slade et al., 2010).

Since the AC-9 has a band pass narrower than the AC-s (10 vs. $15 \mathrm{~nm}$ ), differences are expected between $a_{p}$ spectra collected simultaneously by the two instruments (Dall'Olmo et al., 2012). To make the $a_{p}$ data derived from the AC-s comparable with those derived from the AC-9, we performed an intercalibration by computing the ratio of $a_{p}$ derived from the AC-s to $a_{p}$ derived from the AC-9 at the same $c h l_{o p}$ concentration $( \pm 10 \%)$ for different values of $c h l_{o p}$ concentrations $(n=25$, logarithmically spaced between $0.03-5 \mathrm{mg} \mathrm{m}^{-3}$ ) and for the two wavelengths used in this analysis (i.e., 440 and $676 \mathrm{~nm}$ ). The rationale for this comparison is that, even if collocated spectra of AC-9 and AC-s were not available, for a given $c h l_{o p}$ concentration, we expect that in the open ocean the $a_{p}$ spectra collected by AC-9 and AC-s should, to first order, be comparable. This similarity is a priori expected to be higher at $676 \mathrm{~nm}$, where chl is the most important contributor to $a_{p}$, than at $440 \mathrm{~nm}$, where other optically-active constituents (e.g., detritus, accessory pigments) have higher contributions. We avoided green wavelengths due to the very low values of $a_{p}$, which would significantly increase uncertainties. Average ( \pm standard deviation) $a_{p}{ }^{\mathrm{ACS}}: a_{p}{ }^{\mathrm{AC} 9}$ ratios of $0.68( \pm 0.05)$ and $0.60( \pm 0.02)$ were found at 440 and $676 \mathrm{~nm}$ for AMT-22, and of $0.75( \pm 0.08)$ at $676 \mathrm{~nm}$ for AMT19 irrespective of $c h l_{o p}$. In contrast, during AMT-19 the average $a_{p}{ }^{\mathrm{ACS}}: a_{p}{ }^{\mathrm{AC} 9}$ ratios at $440 \mathrm{~nm}$ varied between 0.90 and 1.4 with $c h l_{o p}$. To account for this variation, we fitted a second-order polynomial $\left(R^{2}=0.97\right)$ between the values of the ratio and $c h l_{o p}$ and used the fitted regression coefficients to calculate $a_{p}{ }^{\mathrm{ACS}}: a_{p}{ }^{\mathrm{AC} 9}$ ratios at $440 \mathrm{~nm}$ for any $c h l_{o p}$ value during AMT19 . We finally corrected the $a_{p}$ values measured by the AC-s 


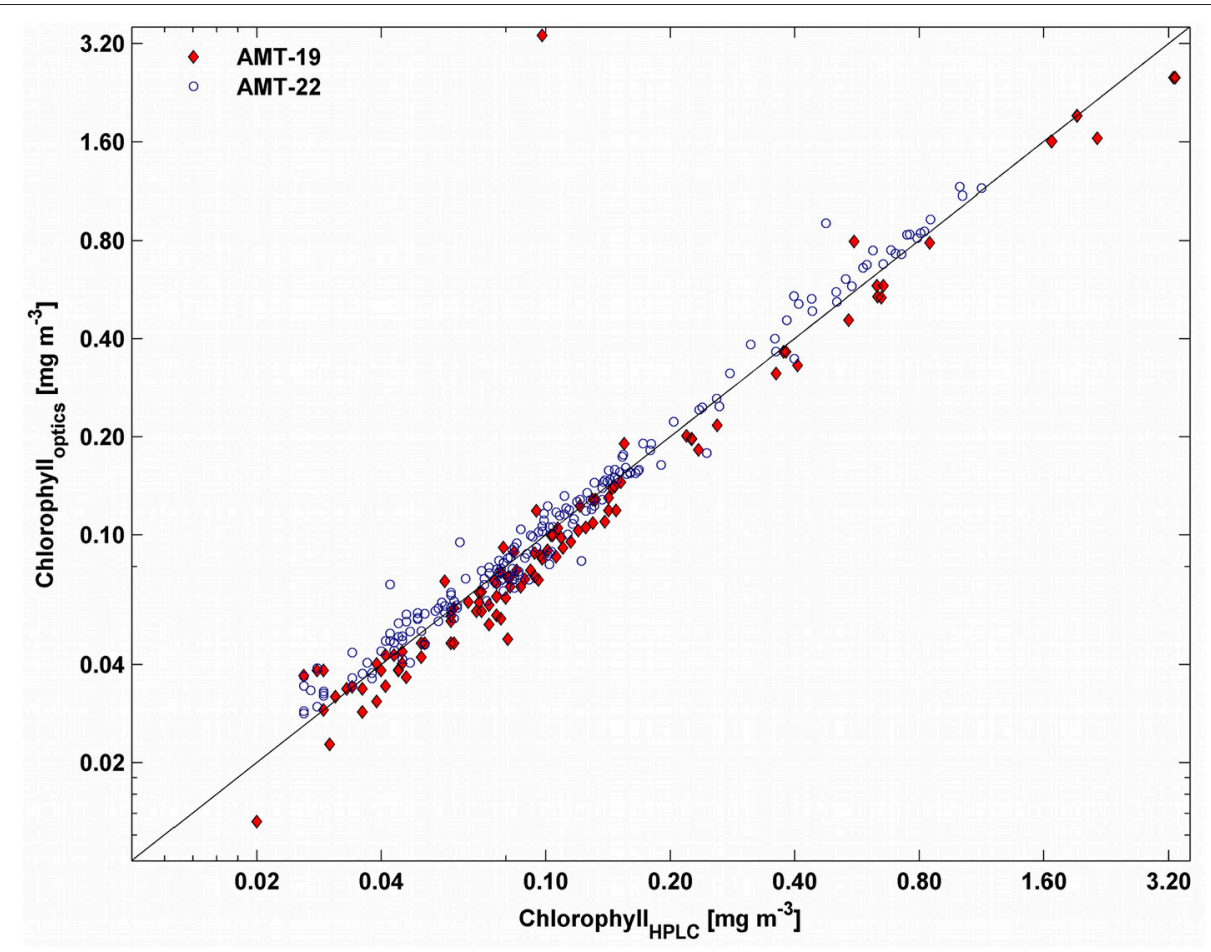

FIGURE 2 | Relationship between chlorophyll-a determined by HPLC and that estimated optically (not bias corrected) for AMT-19 (red diamonds) and AMT-22 (blue circles). The black line indicates the $1: 1$ relationship.

instruments by dividing them by (1) the average ratios found for AMT-19 (at $676 \mathrm{~nm}$ ) and AMT-22 (at 440 and $676 \mathrm{~nm}$ ), and (2) the $a_{p}{ }^{\mathrm{ACS}}: a_{p}{ }^{\mathrm{AC} 9}$ ratios at $440 \mathrm{~nm}$ for a given $c h l_{o p}$ for AMT-19. These corrected $a_{p}$ values were used for the rest of the analysis.

\section{Particulate Backscattering}

Continuous measurements of the particulate backscattering coefficient $\left(b_{b p}\right)$ were carried out by means of a WETLabs ECOBB3 meter $(470,526$, and $660 \mathrm{~nm})$ installed in a flow-through chamber as described in Dall'Olmo et al. (2009 and 2012). More details about the $b_{b p}$ determination as well as the calibration and characterization of the instrument can be found in Dall'Olmo et al. (2009 and 2012) and Behrenfeld et al. (2013, supplementary materials). During AMT-19 flow-through $b_{b p}(470 ; 526)$ data were validated against in-situ $b_{b p}$ values measured with an independent instrument that was deployed on a profiling package (see details in Dall'Olmo et al., 2012). Biases of 16 and 13\% and precisions of 6 and $7 \%$ were found between the two independent methods for the coincident $b_{b p}(470)$ and $b_{b p}(526)$ measurements, respectively and demonstrated that the underway system was clean during AMT-19. Unfortunately, we did not conduct a similar intercalibration during AMT-22.

\section{Particulate Organic Carbon}

Seawater samples $(0.5-41)$ were collected from the ship's clean seawater supply $(\sim 5 \mathrm{~m}$ depth) and filtered through precombusted $\left(4 \mathrm{~h}\right.$ at $450^{\circ} \mathrm{C}$ ) $25-\mathrm{mm}$ Whatman $\mathrm{GF} / \mathrm{F}$ filters under low vacuum $(120 \leq \mathrm{mmHg})$ by open-filter funnels. Each filter was stored in pre-combusted aluminum envelopes, frozen, and stored using the same protocol indicated for HPLC samples, and analyzed in the laboratory after the cruises.

Two methods were used to quantify the contribution of dissolved organic carbon (DOC) adsorbed on the filters (Moran et al., 1999; Gardner et al., 2003). This allowed us to assess their consistency and select the best method to estimate carbon mass retained by the filter blanks. The first method ("interceptblanks") consisted of filtering three volumes of seawater (0.5-1, $0.75-2$, and 2-4) for each sample and regressing the mass of carbon measured on each filter vs. the corresponding volume. The intercept of this regression provided our first estimate of the blank (i.e., mass of carbon present on the filter due to DOC adsorption; Menzel, 1966; Abdel-Moati, 1990; Moran et al., 1999; Gardner et al., 2003; Liu et al., 2005, 2009; Turnewitsch et al., 2007). The second method ("filter-blanks") consisted of refiltering through a clean pre-combusted GF/F filter the filtrate from the sample with the intermediate volume (0.75-2l). These filter blanks were then stored and analyzed as the bulk POC samples.

To determine the POC concentration, filters were first fumed with hydrochloric acid $(12 \mathrm{~N} \mathrm{HCl})$ at room temperature and then POC was determined by standard high-temperature combustion technique (Knap et al, 1996). The cruise-specific average mass of carbon calculated by the intercept-blanks method was removed from each sample as in Cetinić et al. (2012). POC was finally computed as the average concentration derived from the three different volumes collected for each sample. We also estimated 
the average sample mass (POC signal) and mean filter-blank mass (blank) ratio to compute the relative contribution of the blank to the bulk POC signal. The POC signal-to-blank ratio was relatively low in oligotrophic regions (e.g., $\sim 3$, see Figure $3 \mathrm{C}$ ). This therefore indicated that uncertainties in POC measurements could potentially increase in these areas (Moran et al., 1999). To increase the signal-to-noise ratio when it was lower than 3, we calculated POC by excluding the samples with the smallest volume ( $<1$, Moran et al., 1999). Finally, to parameterize biooptical models, we fitted power laws between POC and IOPs. We used log-transformed data to better resolve the bio-optical variability at small POC values as suggested by Campbell (1995).

\section{RESULTS}

\section{Chlorophyll a}

Chlorophyll concentration ranged between 0.02-1.42 and 0.03$1.26 \mathrm{mg} \mathrm{m}^{-3}$ for AMT-19 and AMT-22, respectively (Figure 4A). Similarly, during both expeditions $c h l_{h p l c}$ showed a latitudinal pattern which followed the well-established biogeographical provinces of the Atlantic Ocean (Longhurst, 1998) as in previous AMT cruises (Tarran et al., 2006; Aiken et al., 2009).

\section{POC Measurements}

\section{Mass of Carbon in Blanks}

During AMT-22 both methods for determining the blank carbon mass produced consistent results, with average ( \pm standard deviation) masses for the filter and intercept blanks of 15.5 $\pm 6.5 \mu \mathrm{g} \mathrm{C}(n=196)$ and $14.9 \pm 8.7 \mu \mathrm{g} \mathrm{C}(n=114)$ respectively (Figure 3B). However, for AMT-19, filter-blanks [averages of $24.9 \pm 17.9 \mu \mathrm{g} \mathrm{C}(n=69)$ ] were $\sim 2.3$ times larger than intercept-blanks [averages of $10.9 \pm 8.7 \mu \mathrm{g} \mathrm{C}(n=68)$, Figure $3 \mathbf{A}$ ], indicating a potentially greater contamination of the filter blanks during AMT-19 relative to AMT-22. Nonetheless, the blank values determined in this study with either method were within (or lower than) the range of those reported in the literature (19-25 $\mu \mathrm{g}$ C; Menzel, 1966; Moran et al., 1999; Cetinić et al., 2012), which supports the rigorousness of our POC protocol (e.g., our coefficient of variation had a mean value of 0.06 and ranged between 0.01 and 0.26 ). Since the interceptblank method produced values that were consistent between the two cruises, we used the average intercept-blanks calculated for each cruise separately to derive POC. During AMT-22 4\% of the intercept-blanks were negative (Figure 3D) and these values were mostly located in productive areas of the Atlantic (63\% of the negative intercepts were found where POC $\left.>60 \mathrm{mg} \mathrm{m}^{-3}\right)$.
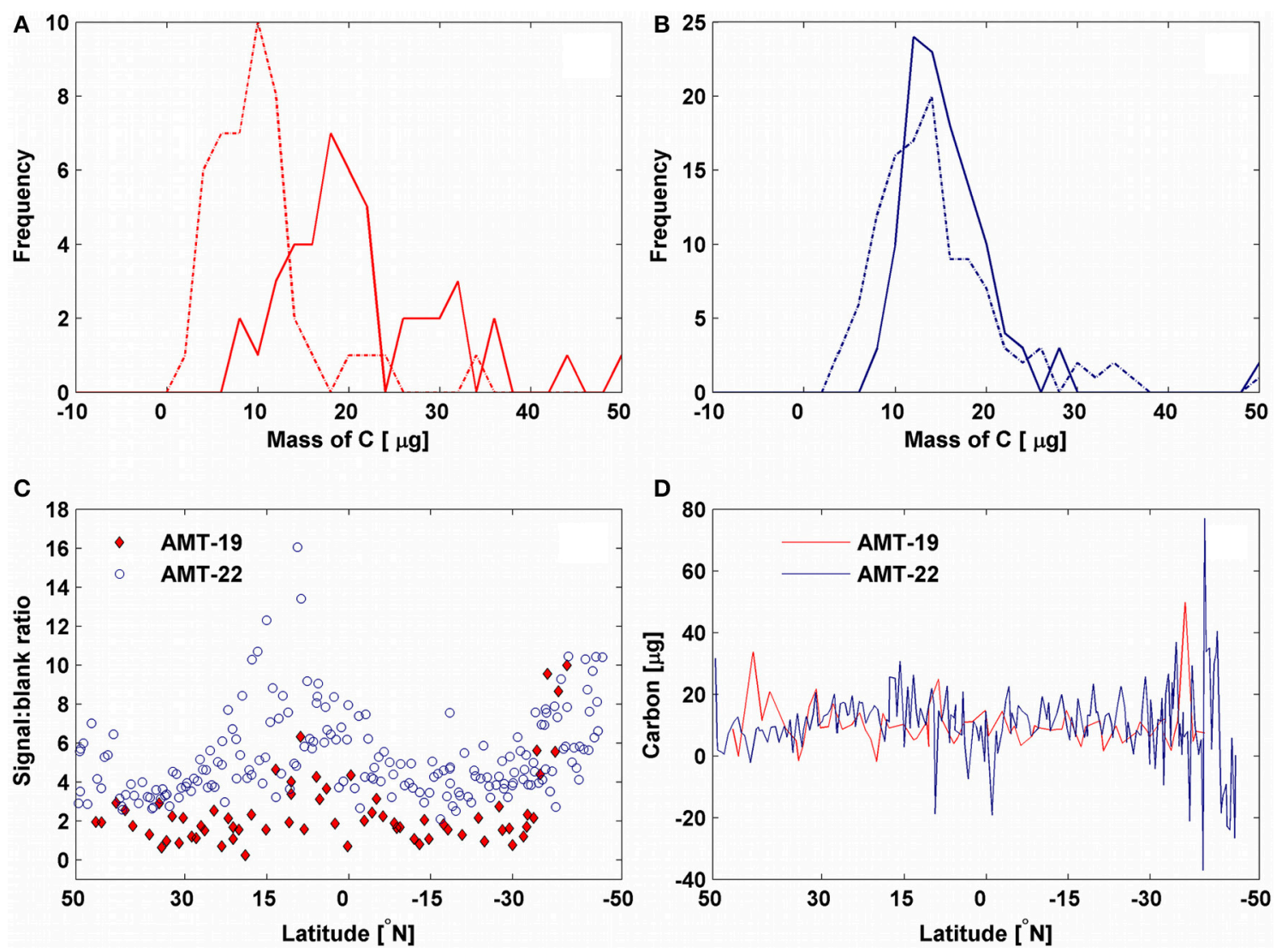

FIGURE 3 | Frequency distribution of the mass of carbon measured by filter-blanks (solid lines) and calculated by intercept-blanks (dash-dot lines) for (A) AMT-19 (red) and (B) AMT-22 (blue). Latitudinal variability of the (C) ratio between mass of carbon in the intermediate-volume samples and mass of carbon in the filter blanks obtained from the corresponding filtrate and (D) mass of carbon on the filter blanks calculated by intercept-blanks for AMT-19 (red) and AMT-22 (blue), respectively. 

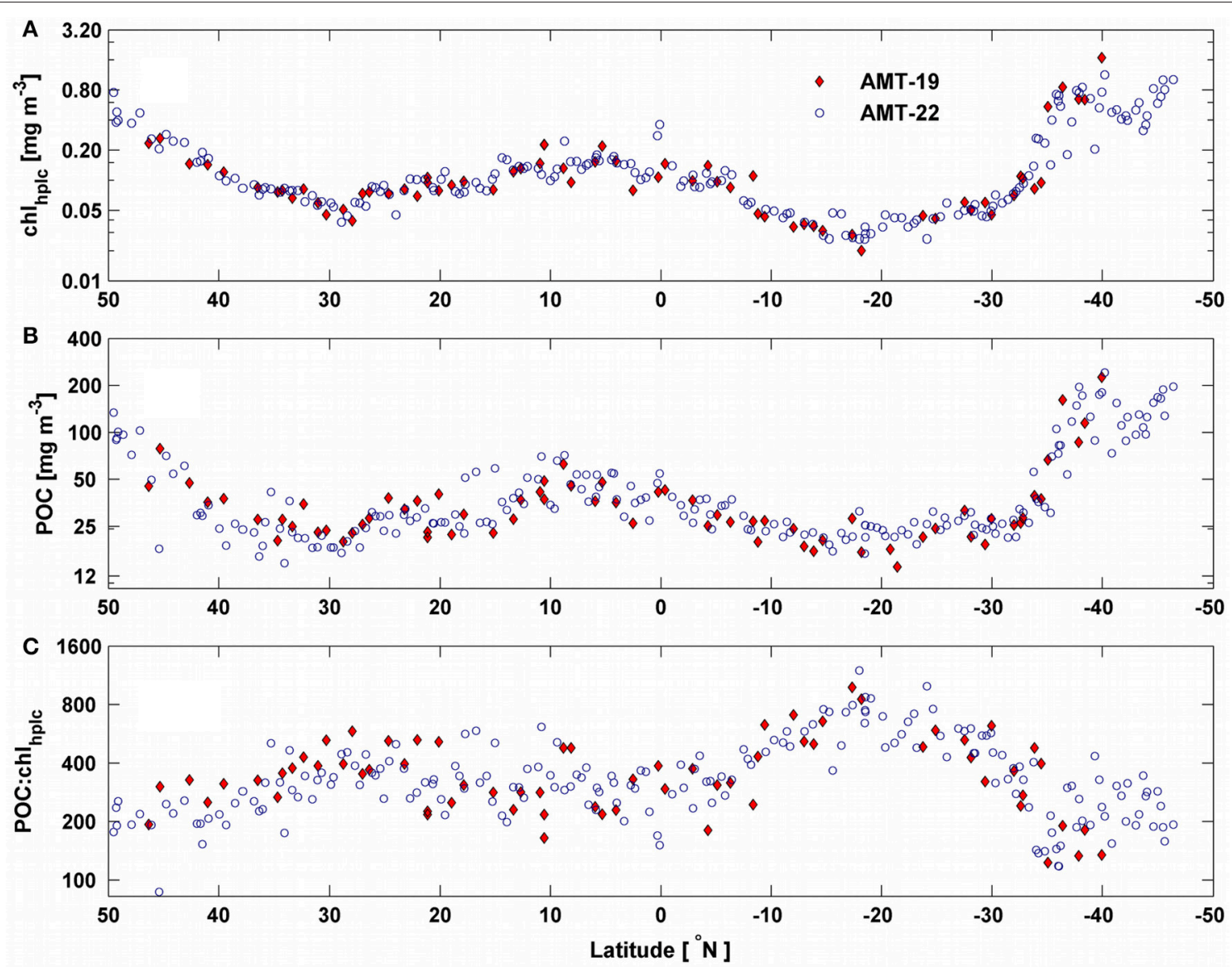

FIGURE 4 | Latitudinal variability of (A) ch/hplc; (B) POC and (C) POC:ch/hplc ratio for AMT-19 (red diamonds) and AMT-22 (blue circles). Note that all y-axes are in log scale.

These negative values are discussed in section POC Blanks and Accuracy.

\section{POC}

The observed range of POC was consistent between the two cruises (15-230 $\mathrm{mg} \mathrm{m}^{-3}$ ) and with previous studies for the Atlantic ocean (Poulton et al., 2006; Balch et al., 2010). POC showed a first-order spatial pattern similar $\left(R^{2}=0.83\right)$ to that of $c h l_{h p l c}$ (Figures 4A,B). However, the POC: $c h l_{h p l c}$ ratio showed an opposite latitudinal pattern (i.e., maxima in the most oligotrophic regions) and varied by a factor of 12 and 14 for AMT-19 and AMT-22, respectively (Figure 4C).

\section{Inherent Optical Properties}

All optical properties showed latitudinal patterns qualitatively similar to those of POC and $c h l_{h p l c}$ during both cruises (Figure 5). While $c_{p}(440)$ and $a_{p}(440)$ values overlapped during both cruises, bulk $b_{b p}(470)$ was on average $30 \%$ larger during AMT-19 than $b_{b p}(470)$ measured during AMT-22 for most of the transect (Figure 5). However, bulk $b_{b p}(470)$ matched when signals measured on $0.2-\mu \mathrm{m}$ were subtracted from the AMT-19 bulk $b_{b p}(470)$ (see detailed explanations in Dall'Olmo et al., 2012). This result suggests that the backscattering signal measured on $0.2-\mu \mathrm{m}$ water can be used to remove biases in flow-through backscattering measurements.

Observed IOPs were well correlated ( $R^{2}$ ranged between $0.71-$ 0.91, Figure 6) with each other. In most cases, power law fits between IOPs and $c h l_{o p}$ were comparable with previous optical models, except for $a_{p}(440)$ vs. $c h l_{o p}$ where the slope was about $66 \%$ steeper than previously reported (equation 4 in Bricaud et al., 1998; Figures 7E,F).

POC and IOPs were correlated during both cruises (Figures 8, 9, Tables 1-3; $R^{2}$ ranged between 0.76-0.95) regardless of the spectral region of the measurement, however, the accuracy of the derived POC-IOPs relationships varied between cruises (2-13\%) and regions of the spectrum (Figures 8, 9, Tables 1-3).

\section{DISCUSSION}

\section{POC Blanks and Accuracy}

Factors such as sample handling, vacuum pressure, and sample volume are known to introduce uncertainties in measured POC which, in turn, affect the accuracy of the relationships between POC and optical properties (e.g., Gardner et al., 2003 and 

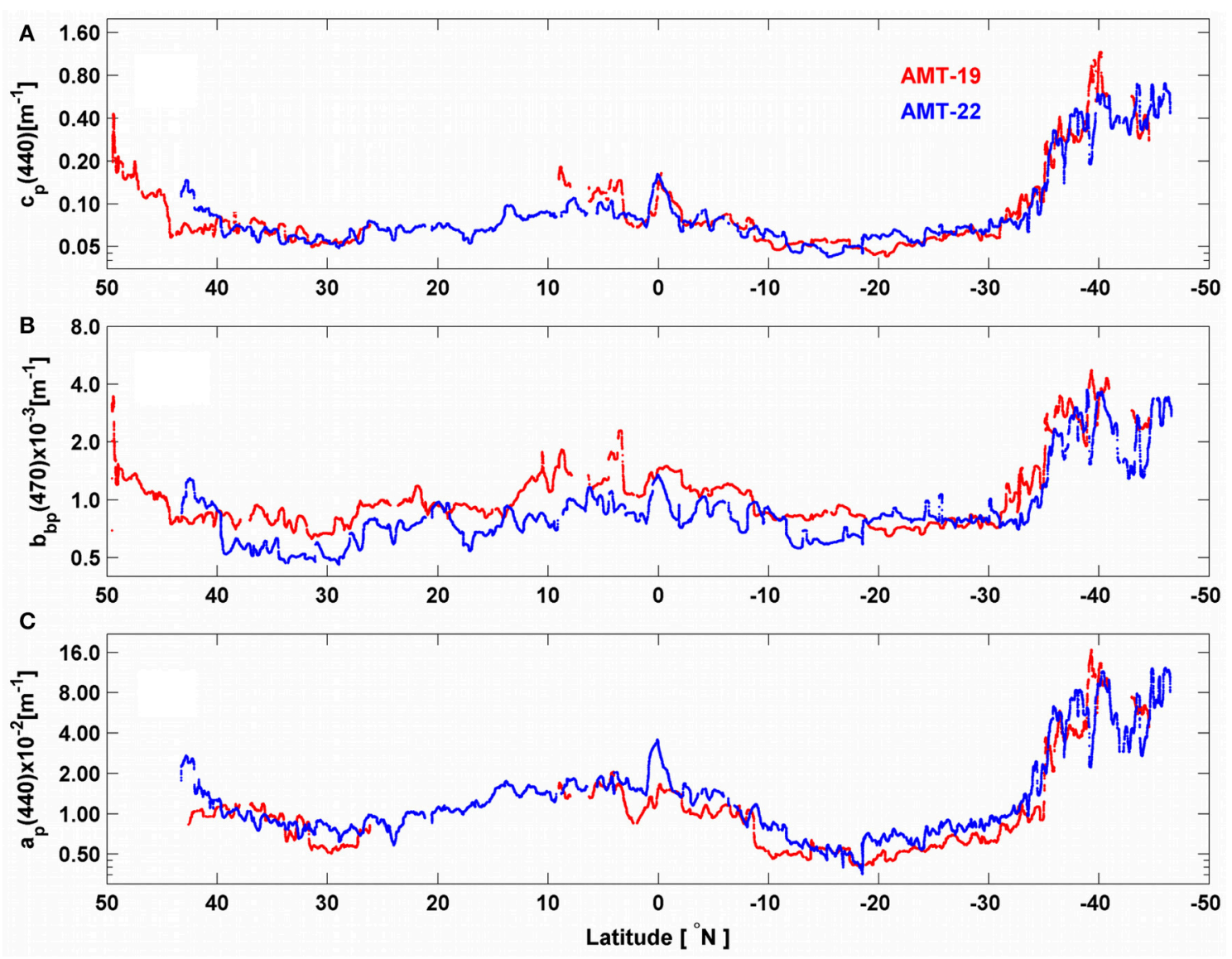

FIGURE 5 | Spatial distribution of (A) $c_{p}(440)$, (B) $b_{b p}(470)$ and (C) $a_{p}(440)$ for AMT-19 (red points) and AMT-22 (blue points). Note that all y-axes are in logarithmic scale.

references therein). In this study we followed recommendations from these previous studies to maximize the accuracy of our POC measurements (see section Particulate Organic Carbon). However, we also assessed how the blank varied between two methods (i.e., intercept-blanks and filter-blanks), along a latitudinal transect, as well as attempted to explain negative intercept-blanks in productive areas.

To explain why filter-blanks were larger than interceptblanks, we hypothesize that by re-filtering the same seawater (as during the filtrate-blanks method) additional sources of contamination and/or uncertainties could be introduced. This may be particularly important in oligotrophic regions where POC is very low and the signal-to-blank ratio reaches its lowest values (Figure 3C). To minimize contamination of blanks, we recommend the use of two stacked GF/F filters as done in previous studies (Menzel, 1967; Liu et al., 2005, 2009; Cetinić et al., 2012), even though filtration times increase considerably.

We further evaluated the latitudinal patterns of the interceptblanks. We found a large number (63\%) of negative intercepts in the southern productive region of the AMT-22 transect (with POC ranging around $60-230 \mathrm{mg} \mathrm{m}^{-3}$, Figure $3 \mathrm{D}$ ). Interestingly, the relationships between carbon mass and filtered volume resulting in negative intercepts were less linear $\left(R^{2}\right.$ statistics were: $\min =0.921 ;$ median $=0.980 ; \max =0.997 ; n=11)$ than for other samples along the transect $\left(R^{2}\right.$ statistics were: $\min$ $=0.965 ;$ median $=0.997 ; \max =0.999 ; n=89 ;$ Figure 10) We hypothesize that this loss of linearity could be due to a saturation of the filters likely caused by the large concentrations of particulate carbon found in these regions. If this was indeed the case, then filters could have become more efficient at retaining POC resulting in the higher carbon masses per unit volume evident in Figure 10. These results indicate that the protocols for determining POC can still be improved.

Toward this aim, we propose to use data from optical transmissometers (commonly available on the ship's rosette) to define the optimal volume of water to be filtered on GF/F filters for determining POC without saturating filters. Our data indicate that linearity in the carbon mass vs. filtered volume relationship was maintained at (1) relatively high values of POC and particulate beam-attenuation coefficient $\left(122 \pm 35 \mathrm{mg} \mathrm{m}^{-3}\right.$ and $0.28 \pm 0.06 \mathrm{~m}^{-1}$, respectively) when filtered water did not exceed 1 liter and (2) at low POC and $c_{p}(650)$ values $(\sim 29 \pm 9 \mathrm{mg}$ $\mathrm{m}^{-3}$ and $\sim 0.04 \pm 0.01 \mathrm{~m}^{-1}$, respectively) when up to 4 liters of seawater were filtered. Therefore, we propose an empirical relationship to estimate the maximum volume to be filtered for POC analysis ( $V_{\text {max }}$, in liters) based on $c_{p}(650)$ (from WETLabs 

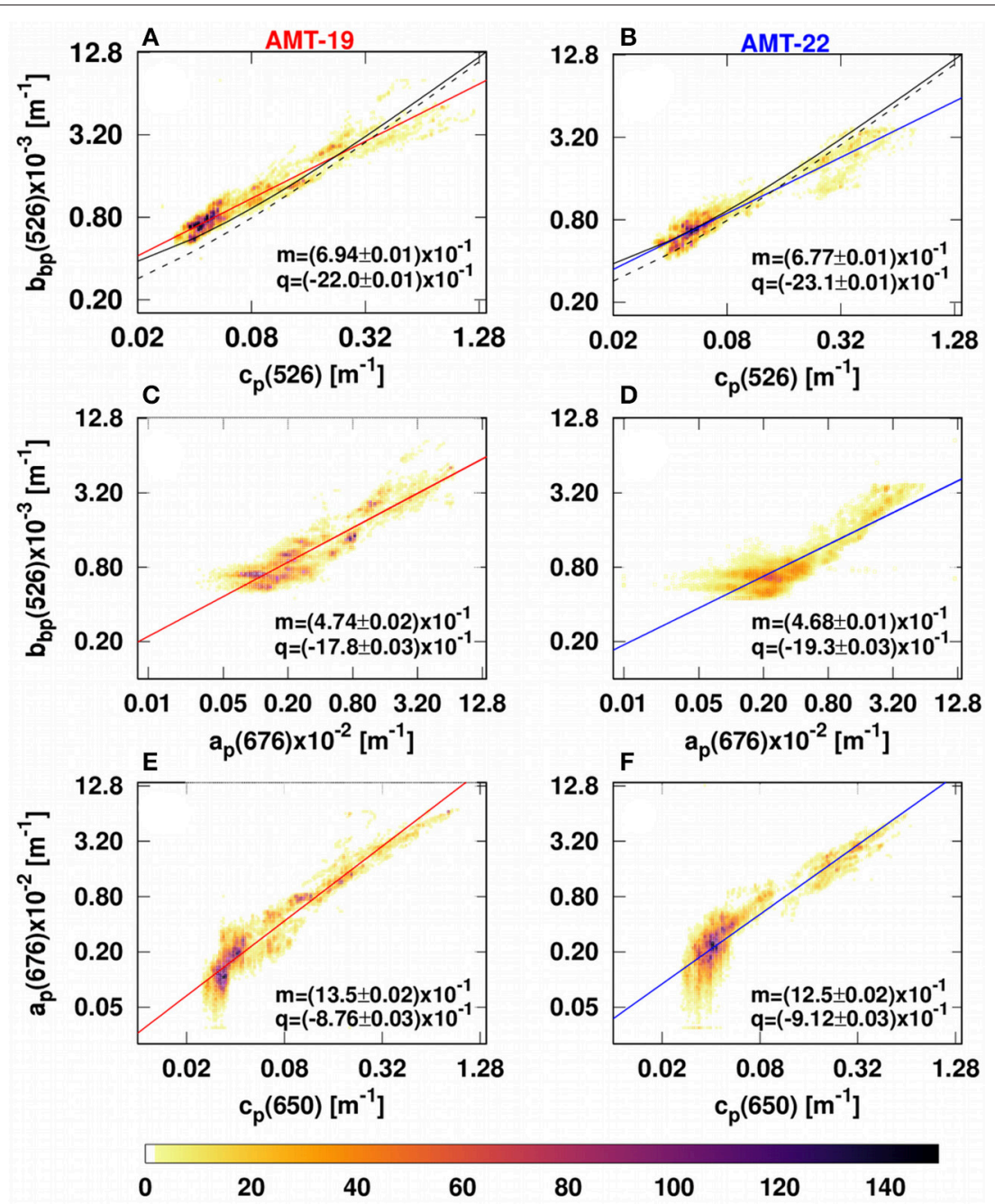

FIGURE 6 | Bivariate histograms showing the relationships between IOPs during AMT-19 (left) and AMT-22 (right). (A,B) Describe $b_{b p}(526)$ vs. $C_{p}(526)$. (C,D) and (E,F) Describe $b_{b p}(526)$ vs. $a_{p}(676)$ and $a_{p}(676)$ vs. $c_{p}(650)$, respectively. The solid and dotted black lines in (A,B) are the prediction from Westberry et al. (2010) and Dall'Olmo et al. (2009) models, respectively. The solid red (left) and blue (right) lines are our best fits for AMT-19 and AMT-22, respectively. The colorbar indicates the number of data points per bivariate bin. Our relationships were fitted using a power law function $\left(\log _{10}\left(I^{O P s}\right)=m \times \log _{10}\left(I^{O O P s}\right)+q\right)$. $c_{p}(650)$ values were measured by a C-star transmissometer.

C-star transmissometer, in $\left.\mathrm{m}^{-1}\right)$ and valid for $c_{p}(650)$ ranging between 0.02 and $0.46 \mathrm{~m}^{-1}$ :

$$
V_{\max }=4.1-7.9 c_{p}(650)
$$

Using this empirical relationship, we predicted $V_{\text {max }}$ for all cases where the intercept was negative and for those positive interceptblank values that were not significantly different from zero. We found that, in most cases, the $V_{\text {max }}$ was lower than the amount of seawater filtered (data not shown). Therefore, we recommend using this empirical relationship to estimate $V_{\max }$ in future studies.

\section{Comparison of IOPs Measurements and Existing Bio-optical Models}

The relationships between $b_{b p}(526)$ and $c_{p}(650)$ vs. $c h l_{o p}$ observed for AMT-19 and AMT-22 (Figure 7) were in agreement with published bio-optical models (Bricaud et al., 1998; Huot et al., 2008; Dall'Olmo et al., 2009; Antoine et al., 2011). Similar results were also obtained for $b_{b p}(526)$ vs. $c_{p}(526)$ (Figures 6C,D). However, our power-law slopes for the $a_{p}(440)$-chl $l_{o p}$ relationship were on average $66 \%$ steeper than that obtained by Bricaud et al. (1998) by their equation 4 (see our Figures 7E,F).

In open-ocean waters, the slope of the $a_{p}(440)$-chl relationship is driven by the absorption of phytoplankton $\left(a_{p h}\right)$ and nonalgal particles $\left(a_{n a p}\right)$ (Bricaud et al., 1998). Nevertheless, $a_{p h}$ would be the main factor determining the slope of the $a_{p}(440)$ chl relationship because it accounts for about $73-80 \%$ of the total $a_{p}(440)$ (Bricaud et al., 1998; Allison et al., 2010a). Therefore, the slope of the $a_{p}(440)$-chl relationship has been mainly attributed to the packaging effect and/or the variability of accessory pigments due to changes in the trophic status (Kirk, 1975; Morel and Bricaud, 1981; Bricaud et al., 1995). Our 

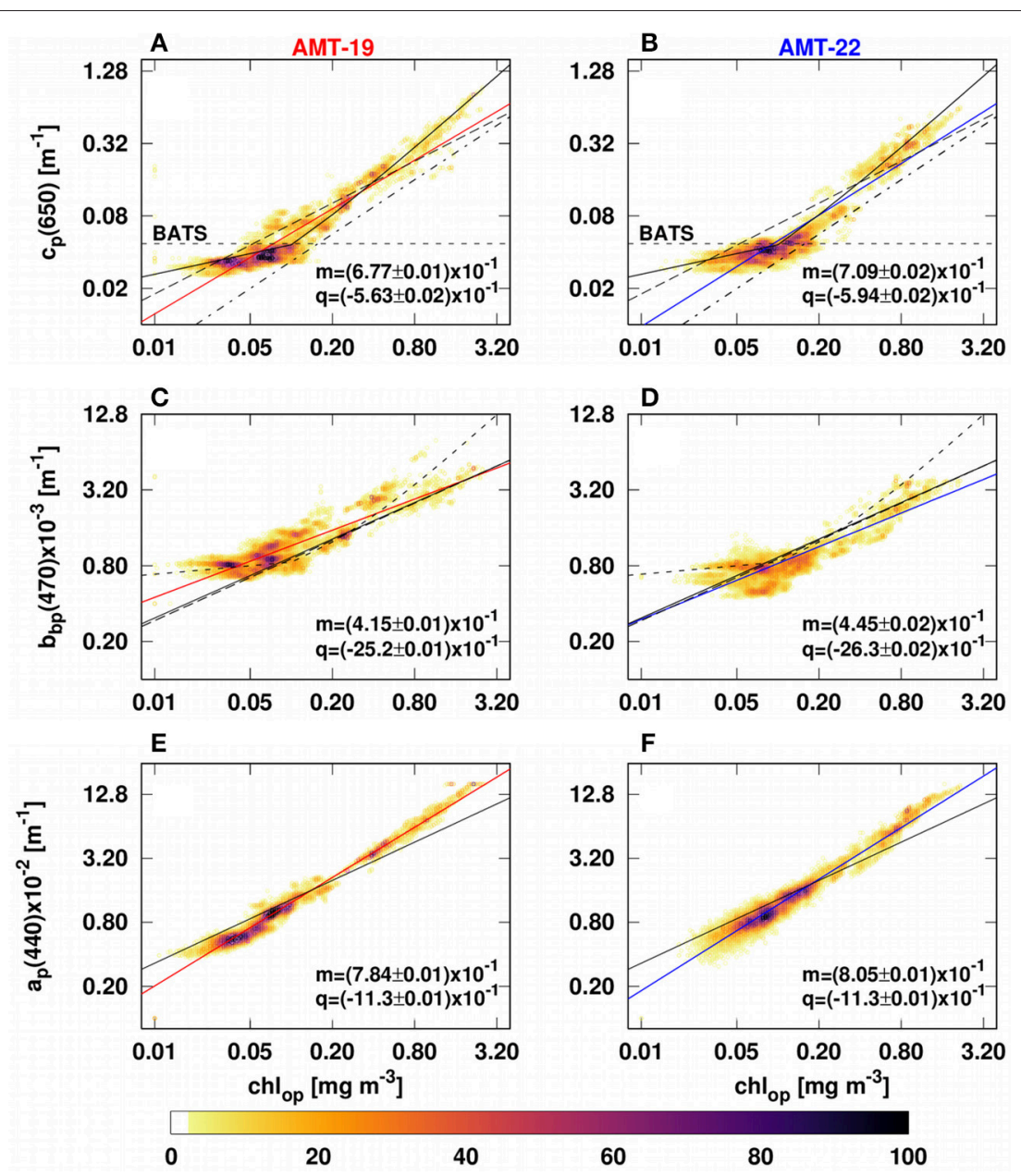

FIGURE 7 | Bivariate histograms showing the relationships between IOPs and chlop during ATM-19 (left) and AMT-22 (right). (A,B) describe $c_{p}$ (650)-C-star vs. chlop. The solid, dashed and dash-dot lines in (A,B) are the linear fits reported by Behrenfeld and Boss (2006), Huot et al. (2008) and Loisel and Morel (1998), respectively. The dotted black line in (A,B) was reported by Behrenfeld and Boss (2006) and it shows that $c_{p}$ and $c h l$ are not correlated in the Bermuda Atlantic Time Series (BATS). (C,D) describe $b_{b p}(526)$ vs. chlop. The solid, dashed and dash-dot lines in (C,D) are the linear fits reported by Antoine et al. (2011), Dall'Olmo et al. (2009) and Huot et al. (2008), respectively. (E,F) describe $a_{p}(440)$ vs. chlop. The black line in (E,F) is the linear fit calculated by Bricaud et al. (1998). The solid red (left) and blue (right) lines are our best fits for AMT-19 and AMT-22, respectively. The color bar indicates the number of data points per bivariate bin. Our relationships were fitted using a power law function $\left(\log _{10}(\right.$ IOPs $)=m \times \log _{10}($ chlop $\left.)+q\right)$.

$a_{p}(440)$-chl $l_{o p}$ relationship suggests that the package effect and/or the variability in accessory pigments may have a smaller influence than expected (Figures 7E,F). Alternatively, the steeper slope of our relationship could be due to an overestimation of $a_{p}(440)$ resulting from lower accuracy of the scattering correction in the blue region of the AC-meter data (Slade et al., 2010).

Another potentially important reason for our steeper slope could be the difference between the methods applied to measure $a_{p}(440)$. While we used optical data derived from the AC-s and AC-9 absorption and attenuation meters, Bricaud et al. (1998) employed the quantitative filter technique (QFT). The QFT concentrates particles on a filter and can result in optical pathlengths of up to $20 \mathrm{~m}$ (Trüper and Yentsch, 1967). This technique requires a correction for pathlength amplification ( $\beta$ factor), that, in most cases, is non-linear and known to introduce uncertainties (Bricaud and Stramski, 1990 and references therein; Allali et al., 1997). By contrast, the pathlength in an AC-s or AC-9 is $25 \mathrm{~cm}$ and no correction for pathlength amplification is needed. Testing whether this methodological difference explains the differences in the chldriven $a_{p}(440)$ bio-optical model is however beyond the scope of this study.

\section{Relationship between POC and $c h l$}

The main challenge in applying chl as POC proxy is the high spatio-temporal variability of the POC:chl ratio due to physiological photoacclimation, variations in the community composition and phytoplankton biomass, and possibly also from variations in the relative contribution of detritus and phytoplankton to the bulk POC (Behrenfeld et al., 2002, 2005, 2015; Gardner et al., 2006 and references therein). Thus, to accurately predict POC from chl, the POC-chl relationships 

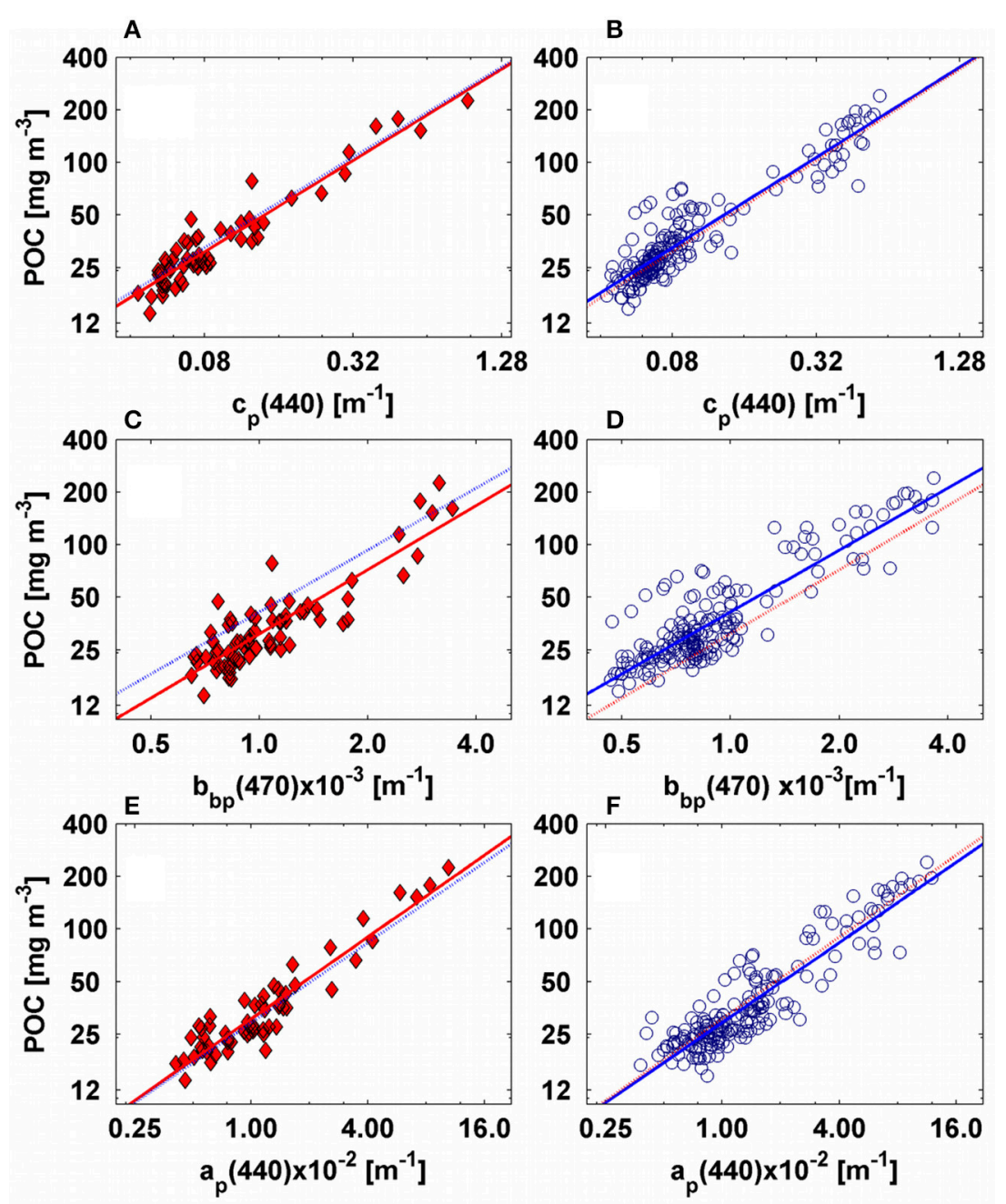

FIGURE 8 | Empirical relationships between POC and IOPs for AMT-19 (left figures, red diamonds) and AMT-22 (right figures, blue circles). For all figures the solid red and blue lines represent our best fits calculated for AMT-19 and AMT-22, respectively. The dotted red and blue lines are the POC predicted by the AMT-19 and AMT-22 empirical relationships, respectively. Plots (A,B) present POC vs. $c_{p}(440)$, while (C,D) present POC vs. b bp (470). (E,F) are POC vs. ap (676).

must (implicitly or explicitly) parameterize the variability in the POC:chl ratio.

The AMT cruise spans a wide range of Atlantic regimes characterized by specific phytoplankton communities acclimated to specific environmental conditions (e.g., prokaryotes and micro-phytoplankton dominate oligotrophic gyres and high temperate latitudes, respectively), (Aiken et al., 2009; MartinezVicente et al., 2013; Graff et al., 2015). As a consequence, we found that the POC:chl ratio varied on average by a factor of 13 during both cruises, with its lowest and largest values in the productive areas and oligotrophic gyres, respectively (Figure 4C). Interestingly, we found similar POC:chl ratios at similar latitudes along the transect during both cruises, likely because we have sampled similar phytoplankton communities acclimated to similar environmental conditions. This similarity between the POC:chl ratios measured at similar latitudes during two independent AMT cruises, suggests that, although the measured range of POC:chl ratios is wide, this ratio is changing in a relatively predictable manner from 1 year to the next at a given latitude. Thus, it should possible to empirically model, at least part of, the variability of the POC:chl.

To test the above hypothesis, we quantified the accuracy of the POC-chl relationships by predicting surface POC for AMT22 by means of the independently-derived power laws fitted from AMT-19 and others studies (see Tables 1, 2, Figure 11). Our POC-chl $l_{h p l c}$ relationship predicted surface POC with a median error (calculated as the difference between the POC measured minus the POC predicted divided by the POC measured and multiplied by 100) that was between 6- and 11-fold lower than those calculated from previous studies (Table 2). We propose that this relatively high level of accuracy is achieved because our model is implicitly parameterizing some of the factors (e.g., community composition, phytoplankton biomass among others) affecting the variability in POC:chl ratio along the Atlantic 

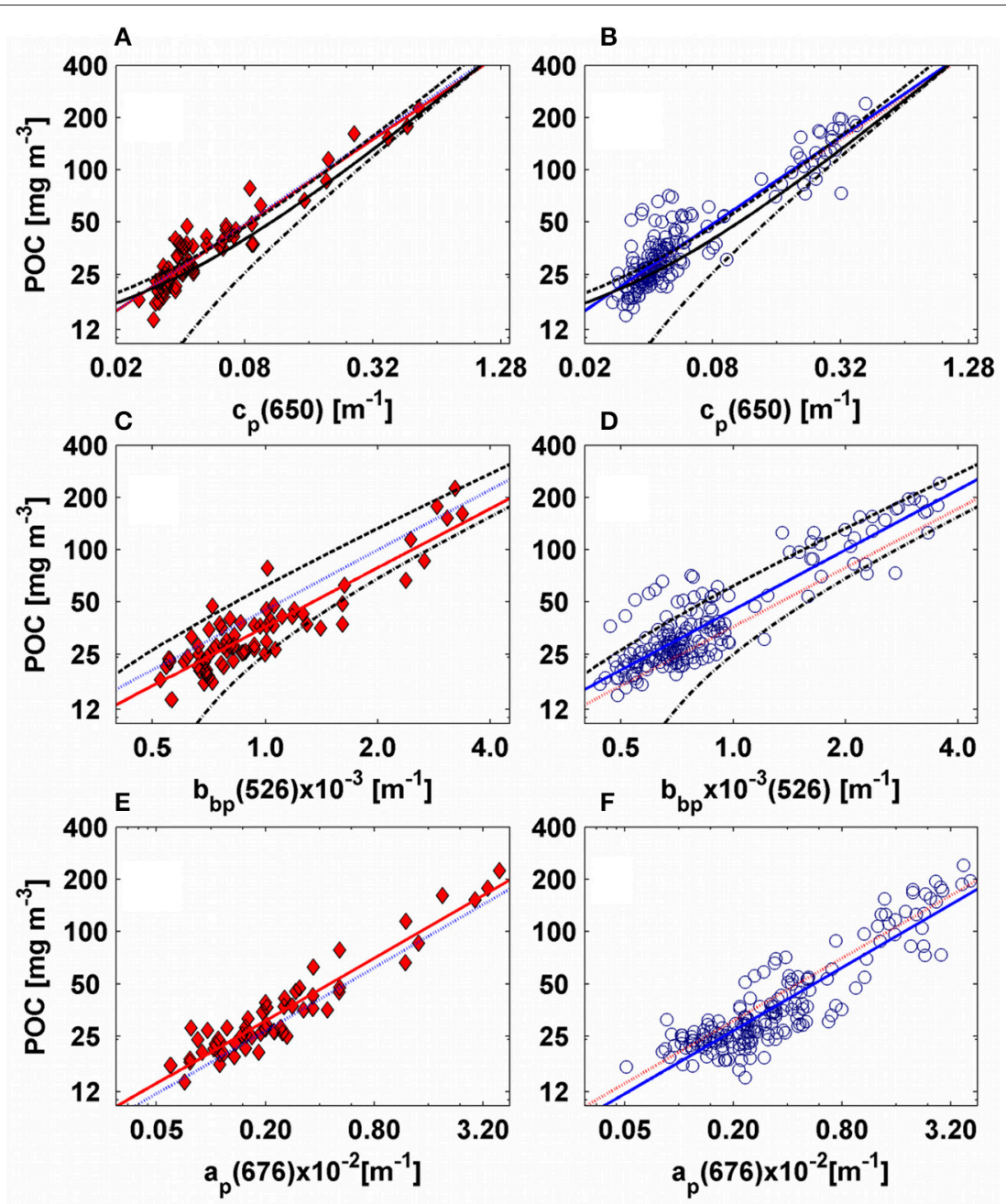

FIGURE 9 | Empirical relationships between POC and IOPs for AMT-19 (left figures, red diamonds) and AMT-22 (right figures, blue circles). For all figures the solid red and blue lines represent our best fits calculated for AMT-19 and AMT-22, respectively. The dotted red and blue lines are the POC predicted by AMT-19 and AMT-22 relationships, respectively. The (A,B) present POC vs. $c_{p}(650)$-C-star, while (C,D) are the POC vs. $b_{b p}(526)$. (E,F) are POC vs. ap (676). From (A-D)

the dashed-dotted and dashed black lines are the linear fits reported by Cetinic et al. (2012) and Stramski et al. (2008) for the corresponding IOP (see Tables 2, 3). In $(\mathbf{A}, \mathbf{B})$ the solid black line is the model reported by Gardner et al. (2006)-global.

transect during this period of the year. However, we cannot argue that this model will accurately predict POC during different seasons or in other ocean regions, because of the expected high variability in the POC:chl ratio (Behrenfeld et al., 2002, 2005, 2015). For example, in oligotrophic regions (e.g., chl <0.10 mg $\mathrm{m}^{-3}$ ) this model could underestimate POC (see Figures 7A,B, 9A,B, 11 in this study and Figures 5B,C in Behrenfeld and Boss, 2006), because in these areas the temporal variability in chl, and thus in the POC:chl ratio, is mostly driven by intracellular changes in phytoplankton pigmentation and not by changes in carbon biomass (Behrenfeld and Boss, 2003, 2006). In other words, we cannot expect that our POC-chl relationship will predict $\mathrm{POC}$ in regions where pigment concentrations are driven by photoacclimation. To demonstrate this, we regressed POC vs. chl using only data with $\mathrm{chl}<0.1 \mathrm{mg} \mathrm{m}^{-3}$ and found that the two variables are poorly correlated $\left(R^{2}\right.$ ranged between 0.14 and 0.33$)$.

\section{Relationships between POC and IOPs Particulate Beam Attenuation Coefficient}

The POC- $c_{p}$ relationship has been extensively tested in the literature (e.g., Gardner et al., 2006; Cetinić et al., 2012 and references therein) and it has been shown that its slope can vary by up to 1.8 -fold between open-ocean regions (Gardner et al., 2006). The power-law fit computed here was similar in the three spectral regions and the POC- $c_{p}(650)$ relationship $\left(c_{p}\right.$ derived from WETLabs C-star transmissometer) was consistent with previous studies, regardless of whether $c_{p}$ was derived with the same or different (e.g., Sea Tech) transmissometers (Figures 9A,B). To compute the accuracy with which the POC$c_{p}(650)$ relationship can predict surface POC, we used the method described above for the POC-chl $l_{h p l c}$ relationship. We found that the POC- $c_{p}(650)$ relationship developed using AMT19 data can predict the POC values of AMT-22 with a median 
TABLE 1 | Empirical relationships between POC, IOPs, and chl for AMT-22.

\begin{tabular}{llccc}
\hline Variables & Instr. & $\boldsymbol{n}$ & $\begin{array}{c}\text { (Slope } \pm \text { std } \\
\text { error) }\end{array}$ & $\begin{array}{c}\text { (Intercept } \pm \text { std } \\
\text { error) }\end{array}$ \\
\hline$c_{p}(440)$ & AC-s & 185 & $0.858 \pm 0.025$ & $2.45 \pm 0.03$ \\
\hline$c_{p}(532)$ & C-star & 185 & $0.838 \pm 0.026$ & $2.52 \pm 0.03$ \\
$c_{p}(650)$ & & 185 & $0.832 \pm 0.027$ & $2.60 \pm 0.03$ \\
\hline$b_{b p}(470)$ & ECO-BB3 & 185 & $1.18 \pm 0.046$ & $5.15 \pm 0.14$ \\
$b_{b p}(470)-b_{b 02}(470)$ & & 184 & $0.853 \pm 0.056$ & $4.20 \pm 0.17$ \\
$b_{b p}(470)-b_{b 02}(470)$ and & & 156 & $0.345 \pm 0.080$ & $2.56 \pm 0.25$ \\
$b_{b p}(470)-<0.00155^{b}$ & & 185 & $1.15 \pm 0.042$ & $5.10 \pm 0.13$ \\
$b_{b p}(526)$ & & 179 & $0.870 \pm 0.054$ & $4.28 \pm 0.17$ \\
$b_{b p}(526)-b_{b 02}(526)$ & & 151 & $0.378 \pm 0.083$ & $2.68 \pm 0.26$ \\
$b_{b p}(526)-b_{b 02}(526)$ and & & & & \\
$b_{b p}(526)<0.0015^{b}$ & & 185 & $0.760 \pm 0.025$ & $2.99 \pm 0.05$ \\
\hline$a_{p}(440)$ & AC-s & 185 & $0.602 \pm 0.022$ & $3.05 \pm 0.05$ \\
$a_{p}(676)$ & & 192 & $0.622 \pm 0.023$ & $2.16 \pm 0.02$ \\
\hline$c h l$ & HPLC & & & \\
\hline
\end{tabular}

a Our optical models are expressed as $\log 10(P O C)=m^{*} \log 10(x)+b$, where $x$ is the corresponding IOP or chl.

${ }^{b}$ The power law function fitted after excluding productive areas and subtracting $b_{b 02}$ from $b_{b p}$.

error of $-2.2 \%$, which was similar or lower than that computed from most published relationships (see Table 2). In addition, our POC $-c_{p}$ relationships have typical uncertainties comparable to our POC-chl $l_{h p l c}$ relationship (Table 2).

On the other hand, the lower predictive accuracy of the POC$c_{p}(660)$ relationship proposed by Cetinić et al. (2012) could be due to the specific temporal and environmental conditions of their study (e.g., North Atlantic spring bloom, dominance of diatoms). If this was the case, then this relationship may need to be considered specific for the North Atlantic bloom periods. Cetinic et al. (2012) report that the lowest POC- $c_{p}$ slopes are found in areas with larger phytoplankton communities (e.g., diatoms with low carbon-cell volume ratio), whereas their largest slopes are found in ocean regions where smaller phytoplankton dominate (e.g., pico-eukaryotes). Similarly, DuRand et al. (2002) indicate that $c_{p}$ per unit of carbon may increase with phytoplankton cell size. Our data are consistent with these earlier studies in that prediction errors of the POC- $c_{p}(660)$ relationship derived by Cetinić et al. (2012) tend to decrease in highlyproductive areas (POC $>60 \mathrm{mg} \mathrm{m}^{-3}$, Figures 9A,B) dominated by larger phytoplankton communities.

The POC $-c_{p}$ relationship has the advantage that $c_{p}(660)$ has been measured during the last decade from oceanographic rosettes. However, $c_{p}$ cannot be derived directly from satellite data and optical transmissometers are not routinely deployed on autonomous platforms. Thus, there is still a need to evaluate other optical proxies of POC.

\section{Factors Affecting Prediction of POC from Particulate Backscattering Coefficient}

As with all inherent optical properties, particulate backscattering covaries to first order with the concentration of suspended matter, but it is also sensitive to changes in particle composition and size, which vary spatially and temporally as a result of external events (e.g., atmospheric deposition) as well as physical (e.g., aggregation-disaggregation) and biogeochemical processes (e.g., mineralization-dissolution) (Stramski et al., 2004a). In addition, it is challenging to measure $b_{b p}$ in the open ocean with high accuracy because of limitations of current sensors (Twardowski et al., 2007; Dall'Olmo et al., 2012). This optical property, however, has the advantages of being retrievable from ocean-color remote sensing and being measured in situ by autonomous platforms. Thus, $b_{b p}$ has been used as a proxy of POC in open-ocean waters where optical properties are dominated by biogenic organic matter (Morel and Prieur, 1977; Smith and Baker, 1978; Stramski et al., 2008).

We computed power-law fits between POC and $b_{b p}$ for two spectral regions (470 and $526 \mathrm{~nm}$, Tables 1, 3, Figures 8, 9). We found that the slopes of the relationships were almost equivalent between the cruises (Tables 1, 3), and we thus concluded that the underway system was also clean during AMT-22 (see also the section Particulate Backscattering). However, the POC- $b_{b p}(470)$ relationship derived during AMT-19 predicted POC with the largest median error (25\%, Table 3). Dall'Olmo et al. (2012) reported that during AMT-19 relatively large $b_{b p}$ signals were measured on $0.2-\mu \mathrm{m}$ filtered seawater, likely due to a small, but unidentified bias in their $b_{b p}$ measurements. We therefore subtracted the $0.2 \mu \mathrm{m}$ filtered signal $\left(b_{b 02}\right)$ from $b_{b p}$ to reevaluate our POC relationships (Figure 12). Resultant median errors for the POC- $b_{b p}(470)$ and POC- $b_{b p}(526)$ relationships decreased by 7 - and 2-fold, respectively (Table 3, Figure 12). These results indicate that even small biases in $b_{b p}$ measurements can significantly affect the accuracy of the POC- $b_{b p}$ relationship.

Additional factors that can affect the accuracy of POC- $b_{b p}$ relationships between independent studies are: (1) uncertainties of POC estimates, (2) uncertainties in $b_{b p}$ measurements, and (3) variability in the particles assemblages between regions (Gardner et al., 2006; Stramski et al., 2008; Cetinić et al., 2012). Published POC- $b_{b p}$ relationships predict biased estimates (by $\sim \pm 60 \%$ ) of surface POC measured during AMT-22 (Table 3, Figure 9). The POC- $b_{b p}(555)$ relationship proposed by Stramski et al. (2008) is based on data collected in waters similar to those found during AMT (e.g., similarly to our dataset, POC, POC:chl and $b_{b p} / b_{p}$ ratios measured by Stramski et al. (2008), range between 12 and $270 \mathrm{mg} \mathrm{m}^{-3}, 100-1,000$, and $0.007-0.018$, respectively). This relationship, however, was developed using $b_{b p}$ data measured by Hydroscat- 6 and a- $\beta$ eta sensors (calibrated by the plaque method) installed on a CTD-rosette, whereas we used an ECO$\mathrm{BB}$ sensor (calibrated by the micro-sphere method) installed in a flow-through chamber connected to the ship's underway system (see detail description in Dall'Olmo et al., 2009, 2012). The prediction error of the Stramski et al. (2008) POC- $b_{b p}(555)$ relationship (median error of $-27 \%$ ) was slightly higher than that found in this study (Table 3). However, their prediction error was within the range (in absolute value) of the uncertainties in $b_{b p}$ measurements (20-40\%, Dall'Olmo et al., 2012). We therefore suggest that the difference between the POC- $b_{b p}$ relationships derived from Stramski et al. (2008) and in this study could be due to the different methods applied to measure $b_{b p}(526)$, as well as uncertainties in $b_{b p}$ measurements. This hypothesis is supported 
TABLE 2 | Accuracy of AMT-19 bio-optical relationships to predict surface POC measured during AMT-22.

\begin{tabular}{|c|c|c|c|c|c|c|c|}
\hline \multirow[t]{2}{*}{ Variables } & \multirow[t]{2}{*}{ References } & \multirow[t]{2}{*}{ Instr. } & \multirow[t]{2}{*}{$N$} & \multirow[t]{2}{*}{ (Slope \pm std error) } & \multirow[t]{2}{*}{ (Intercept \pm std error) } & \multicolumn{2}{|c|}{ a Performance in predicting POC } \\
\hline & & & & & & Median & $\mathbf{S R}^{\mathbf{b}}$ \\
\hline$c_{p}(532)$ & & C-star & 68 & $0.829 \pm 0.036$ & $2.51 \pm 0.04$ & -2.5 & 22.2 \\
\hline$c_{p}(650)$ & & & 68 & $0.822 \pm 0.035$ & $2.58 \pm 0.05$ & -2.2 & 22.8 \\
\hline$c_{p}(660)$ & [2] & C-star & 59 & 458.3 & 10.3 & -6.4 & 25.0 \\
\hline$c_{p}(660)$ & [3] & & 296 & $391 \pm 19$ & $-5.8 \pm 5.5$ & 60.7 & 14.4 \\
\hline$a_{p}(440)$ & This study & AC-s/AC-9 & 57 & $0.776 \pm 0.038$ & $3.04 \pm 0.07$ & -6.4 & 26.4 \\
\hline$c h l$ & [4] & HPLC & 409 & 90 & 0.57 & 29.8 & 22.3 \\
\hline $\mathrm{chl}$ & [5] & HPLC & 77 & 35.8 & 22.2 & 15.6 & 32.8 \\
\hline
\end{tabular}

aThe residual was calculated as the difference between the POC measured and predicted divided by the POC measured.

${ }^{b}$ SR: Spread of the residuals around the median computed as half the difference between the 84th and 16th percentile.

${ }^{c}$ QFT: quantitative filters technique.

[1,2,3] Relationships between POC vs. IOPs found by ${ }^{[1]}$ Gardner et al. (2006) for Global oceans, ${ }^{[2]}$ Stramski et al. (2008) for Atlantic-Pacific, and ${ }^{[3]}$ Cetinić et al. (2012) for North Atlantic. Models derived from d, e and $f$ are expressed as POC $=m^{*} x+b$, where $x$ is the corresponding IOP. For Stramski et al. (2008) we used POC vs. $c_{p}$ model that includes all data.

[4] Power law fitted $\left(P O C=90(\mathrm{chl} /)^{0.57}\right)$ by Loisel and Morel (1998) for world oceans.

[5] Linear regression (POC $=m^{*} \mathrm{chl}+$ b) computed by Stramska and Stramski (2005) for North Polar Atlantic spring.

[This study] Our optical models are expressed as $\log 10(P O C)=m^{*} \log 10(x)+b$, where $x$ is the corresponding IOP or chl.

TABLE 3 | Accuracy of POC- $b_{b p}$ models derived from AMT-19 in predicting surface POC measured during AMT-22.

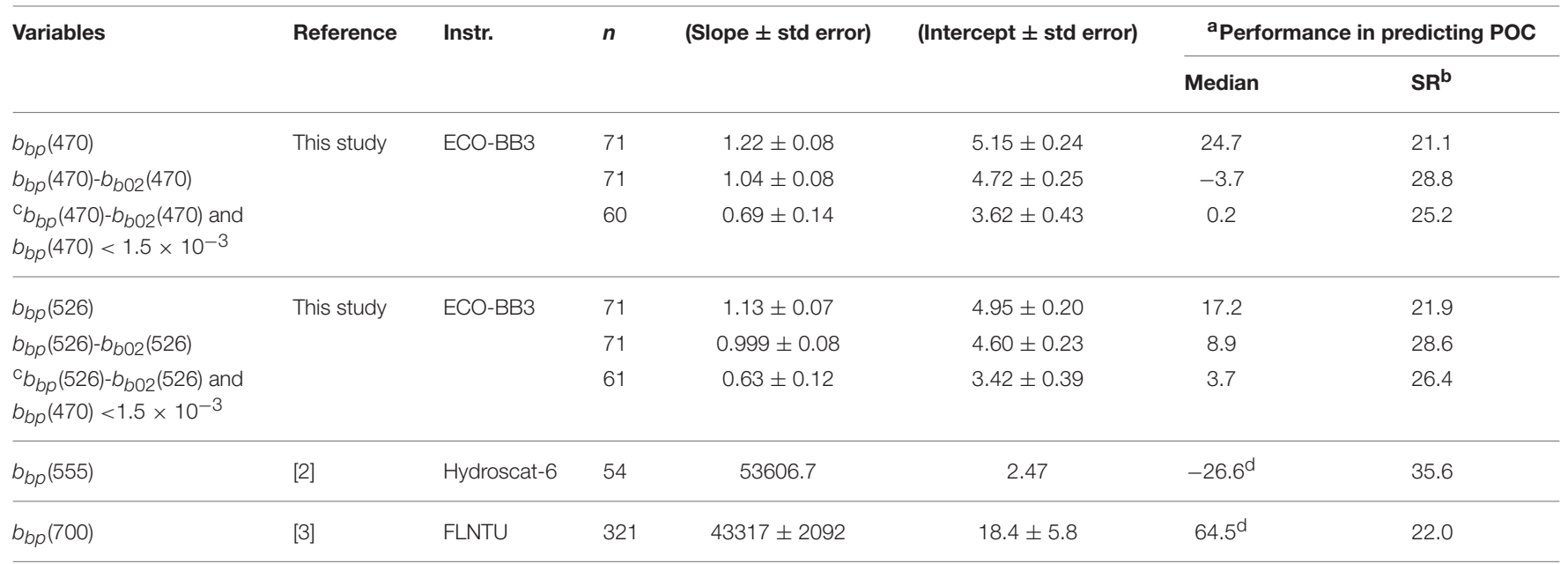

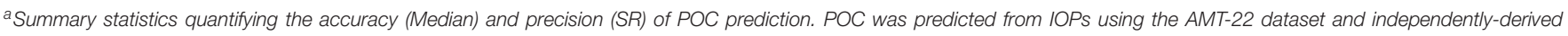
bio-optical relationships. Residuals were calculated as the difference between the POC measured minus the POC predicted divided by the POC measured and multiplied by 100.

bSR: spread of the residuals around the median computed as half the difference between the 84th and 16th percentile (this is a robust version of the standard deviation).

${ }^{c}$ Relationships that exclude data from productive areas ( $P O C>60 \mathrm{mg} \mathrm{m}^{-3}$ and $\left.b_{b p}>1.5 \times 10^{-3} \mathrm{~m}^{-1}\right)$.

${ }^{d}$ To test the accuracy of the reported POC- $b_{b p}$ relationships we used the $b_{b p}(526)$ signal after subtract the $b_{b p}(526)$ of filtered seawater.

[This study] Our optical models are expressed as $\log _{10}(P O C)=m^{*} \log 10\left(b_{b p}\right)+b$.

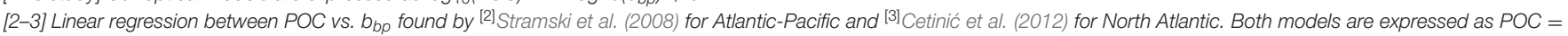
$m^{\star} b_{b p}+b$. For Stramski et al. (2008) we used POC vs. bbp (555) relationship that excludes upwelling data. 

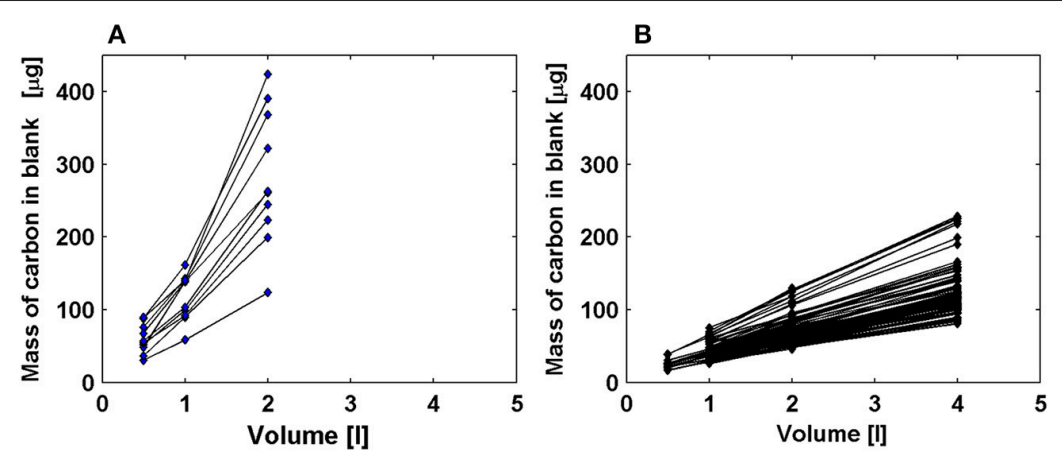

FIGURE 10 | Relationship between mass of carbon and volume of seawater filtered for (A) data with negative intercepts significantly different from zero and located in high latitudes (POC $>60 \mathrm{mg} \mathrm{m}^{-3}$ ) and $\mathbf{( B )}$ data with positive intercepts significantly different from zero in oligotrophic areas (POC < $\left.60 \mathrm{mg} \mathrm{m}^{-3}\right)$. Figures only include data from AMT-22.
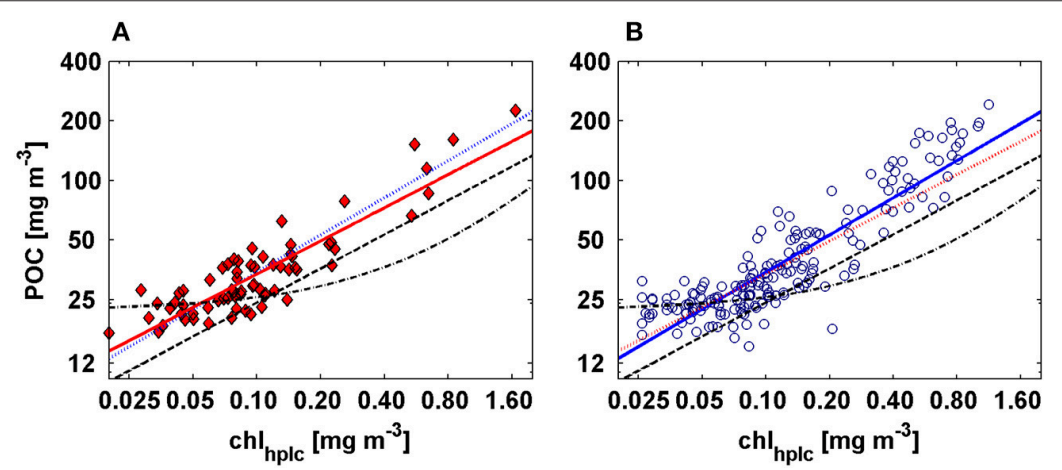

FIGURE 11 | Power law relationship fitted between POC vs. ch/hplcfor AMT-19 (red diamonds) and AMT-22 (blue circles). The solid red and blue lines represent our best power law fits calculated for AMT-19 and AMT-22, respectively. Dashed and dashed-dotted black lines are the relationships computed by Loisel and Morel (1998) and Stramska and Stramski (2005), whereas the dotted red and blue lines are the POC predicted from AMT-19 and AMT-22 POC-chl hplc models, respectively.
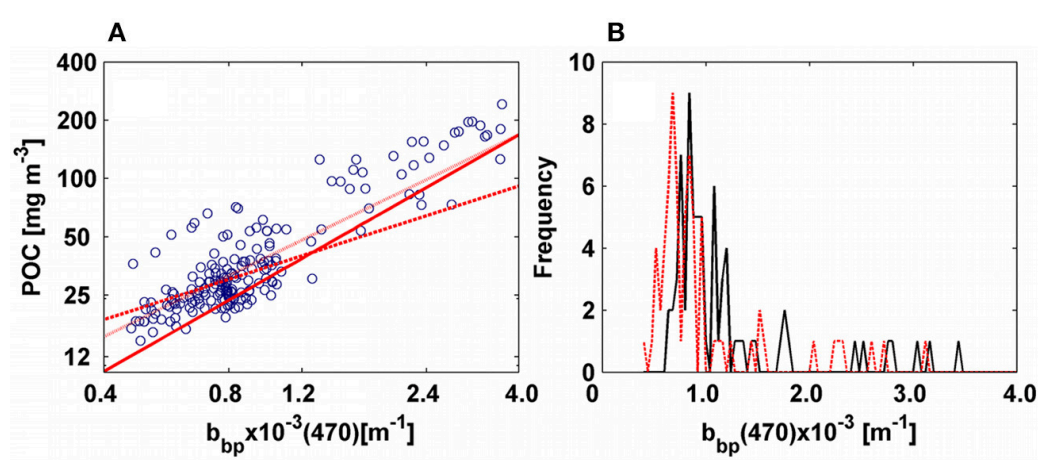

FIGURE 12 | (A) Correlation between POC and $b_{b p}(470)$. Blue circles are data from AMT-22. Solid red line is the power law fitted for AMT-19. Dotted red line is the power function computed after subtracting $b_{b 02}$ from $b_{b p}$. Dashed red line is the power law function fitted after excluding productive areas and subtracting $b_{b 02}$ from $b_{b p}$. (B) Relative distribution of $b_{b p}$ for AMT-19. Solid black line is the $b_{b p}$ data and dashed red line is $b_{b p}$ minus $b_{b 02}$.

by the agreement found between the $\mathrm{POC}-c_{p}$ relationships of Stramski et al. (2008) and in this study in the red spectral region (Table 2, Figure 9).

The Cetinić et al. (2012) POC- $b_{b p}(700)$ relationship underestimated by $60 \%$ the POC measured during AMT-22 and we hypothesize this is due to the different protocols used for measuring $b_{b p}$ and/or different wavelengths (for example, see Table 3), as explained above. However, the difference between the structural compositions of the particles between studies seems to be a significant factor determining 
the accuracy of their POC- $b_{b p}$ relationships. For example, large phytoplankton assemblages predominated (diatoms with low carbon:volume-cell ratio) in Cetinić et al. (2012), whereas small and large phytoplankton assemblages were included in our case. Interestingly, and similar to what was found for the POC- $c_{p}(660)$ relationship, the relative errors in POC prediction derived from their POC- $b_{b p}(700)$ relationship fell to the lowest values in productive areas (Figure 9).

It is also reasonable to suggest that uncertainties in the Cetinic et al. (2012) POC measurements (POC $<60 \mathrm{mg} \mathrm{m}^{-3}$ ) could be another factor that contributed to the difference between their predicted POC and those measured for AMT-22 in oligotrophic regions (Figure 9). For example, to increase the POC signalto-blank ratios and decrease potential uncertainties in places with low POC concentration (POC $<60 \mathrm{mg} \mathrm{m}^{-3}$, see sections Particulate Organic Carbon and Figure 3C), we calculated POC by using samples with the largest volume of seawater filtered (the volumes of the samples were $\geq 21$ for $80 \%(n=296)$ of our POC measurements in these areas). As a result, low standard deviations were found for oligotrophic POC concentration (POC concentration in oligotrophic regions (mean \pm standard deviation $\left.)=(27.2 \pm 1.42) \mathrm{mg} \mathrm{m}^{-3} ; n=148\right)$. In contrast, Cetinić et al. (2012) calculated POC by using smaller volumes (1.11) than those used here for a similar range of POC $\left(<60 \mathrm{mg} \mathrm{m}^{-3}\right)$. This in turns could decrease their POC signal-to-blank ratios and increase the errors in their POC measurements (Moran et al., 1999).

During both cruises, we sampled trophic states (oligotrophic and eutrophic) characterized by different POC concentration and structural composition of the particle assemblages. For example, the greatest POC concentration and the lowest POC:chl $l_{h l c}$ ratios were found in the productive areas (Figure 4). In these areas, large phytoplankton cells are also typically observed. Therefore, the influence of POC concentration and particle assemblages in the accuracy of POC- $b_{b p}$ relationships was assessed by excluding POC and $b_{b p}$ data from productive areas (POC $>60 \mathrm{mg} \mathrm{m}^{-3}$, which is equivalent to $\sim \mathrm{b}_{\mathrm{bp}}>1.5 \times 10^{-3} \mathrm{~m}^{-1}$ ) and by reevaluating the relationships. The prediction error of the POC$b_{b p}$ relationships did not decrease significantly (only by $4 \%$, Table 3), because approximately $80 \%$ of our data are located in oligotrophic regions. However, with the revised relationships the POC was underestimated by $55 \%( \pm 14)$ in productive areas (Figure 12). Similarly, Stramski et al. (2008) found that their POC- $b_{b p}(500)$ slope decreased by 1.3 -fold when they excluded POC- $b_{b p}$ data from productive upwelling regions. These results corroborate the suggestion that, to derive robust global POC$b_{b p}$ relationships, it is important to include POC- $b_{b p}$ data from different trophic states (e.g., Gardner et al., 2006).

\section{Predicting POC from Particulate Absorption Coefficient}

The variability in the particulate absorption coefficient is driven by the variability in particulate organic and inorganic components (phytoplankton biomass, biogenic detritus, bacteria, atmospheric dust), (Bricaud et al., 1998; Stramski et al., 2004b). Because POC potentially comprises all the organic components mentioned above and because the concentration of inorganic material is generally low in the surface open-ocean, we expect to find correlations between POC and $a_{p}$. As an example, a relatively strong relationship exists between $\mathrm{POC}$ and remote-sensing reflectance ratios and the latter quantity is mainly dependent on $a_{p}$ in the surface open-ocean (Allison et al., 2010a). Indeed, in our study, the relationships based on $a_{p}$ predicted POC with a median error of -6.4 and $-12.6 \%$ in the blue and red spectral regions, respectively (Table 2 ). The POC- $a_{p}$ relationships, however, also depends on the variability in POC:chl ratios, because $a_{p}$ is mostly driven by phytoplankton pigments in the surface open ocean (Bricaud et al., 1998; Allison et al., 2010a), (section Relationship between POC and $(h l)$. Therefore, the arguments that explain why we can predict POC from $a_{p}$ in this study, and why we cannot warrant application of this model to other seasons or other ocean regions, are the same as described above for the POC chl relationship (section Relationship between POC and chl). Nevertheless, the median prediction error of $a_{p}(440)$ is similar to those computed for $c_{p}$ and $b_{b p}$ (Tables 2, 3), and $a_{p}(440)$ can be retrieved from remote sensing (e.g., Mitchell et al., 2014). We therefore suggest that, similarly to $c h l, a_{p}$ could be used as a global POC proxy, only when the factors affecting the variability in the POC:chl ratio are accounted for in the bio-optical model (e.g., Behrenfeld et al., 2015; Arteaga et al., 2016).

\section{CONCLUSIONS}

We found empirical POC-IOPs relationships that can predict independently-measured POC with a median error of about $\pm 10 \%$. We showed that our POC-IOPs relationships predicted POC with equal or greater precision than those predicted from previous POC-IOPs and POC-chl relationships. We conclude that the differences found between $\mathrm{POC}-c_{p}$ and POC- $b_{b p}$ relationships from previous studies and those found here, were due to differences between (1) the protocols applied for measuring POC and IOPs, and (2) the characteristics of the particle assemblages in the sampled ocean regions.

To our best knowledge, we reported for the first time POC$a_{p}$ relationships for the surface oligotrophic open ocean. We found that the POC- $a_{p}(440)$ relationship predicted POC with accuracy comparable to those predicted from the traditional ones (e.g., POC- $b_{b p}$, POC- $c_{p}$, and POC-chl). However, we warn that before $a_{p}(440)$ or $c h l$ could be considered as alternative POC proxies, bio-optical models should account for the factors driving the large variability in POC:chl ratio that is expected due to physiological photoacclimation.

We finally conclude that our POC- $b_{b p}$ and POC- $c_{p}$ relationships are robust and can estimate POC in surface open-ocean waters of the Atlantic with the accuracies of the order of $10 \%$.

\section{AUTHOR CONTRIBUTIONS}

The dataset used in this study was collected by the Oregon State University Group (GD, JG, TW, VvD-V, and MB) and processed by RR and GD. RR developed and tested the empirical 
relationships, and wrote the first version of the manuscript. All authors commented on and contributed to the improvement of the final version of the manuscript.

\section{ACKNOWLEDGMENTS}

The authors would like to thanks to the UK National Academy and to the Royal Society for the support provided by the

\section{REFERENCES}

Abdel-Moati, A. R. (1990). Adsorption of dissolved organic carbon (DOC) on glass fiber filters during particulate organic carbon (POC) determination. Water Res. 24, 763-764. doi: 10.1016/0043-1354(90) 90033-3

Aiken, J., Pradhan, Y., Barlow, R., Lavender, S., Poulton, A., Holligan, P., et al. (2009). Phytoplankton pigments and functional types in the Atlantic Ocean: a decadal assessment, 1995-2005. Deep Sea Res. 56, 899-917. doi: 10.1016/j.dsr2.2008.09.017

Allali, K., Bricaud, A., and Claustre, H. (1997). Spatial variations in the chlorophyllspecific absorption coefficients of phytoplankton and photosynthetically active pigments in the equatorial Pacific. J. Geophys. Res. Oceans 102, $12413-12423$.

Allison, D. B., Stramski, D., and Mitchell, B. G. (2010a). Empirical ocean color algorithms for estimating particulate organic carbon in the Southern Ocean. J. Geophys. Res. Oceans 115:C06002. doi: 10.1029/2009JC 006040

Allison, D. B., Stramski, D., and Mitchell, B. G. (2010b). Seasonal and interannual variability of particulate organic carbon within the Southern Ocean from satellite ocean color observations. J. Geophys. Res. Oceans 115:C10044. doi: 10.1029/2009JC005347

Antoine, D., Siegel, D. A., Kostadinov, T., Maritorena, S., Nelson, N. B., Gentili, B., et al. (2011). Variability in optical particle backscattering in contrasting bio-optical oceanic regimes. Limnol. Oceanogr. 56, 955-973. doi: 10.4319/lo.2011.56.3.0955

Arteaga, L., Pahlow, M., and Oschlies, A. (2016). Modeled Chl:C ratio and derived estimates of phytoplankton carbon biomass and its contribution to total particulate organic carbon in the global surface ocean. Glob. Biogeochem. 30, 1791-1810. doi: 10.1002/2016GB005458

Balch, W. M., Bowler, B. C., Drapeau, D. T., Poulton, A. J., and Holligan, P. M. (2010). Biominerals and the vertical flux of particulate organic carbon from the surface ocean. Geophys. Res. Lett. 37, L22605. doi: 10.1029/2010GL0 44640

Behrenfeld, M. J., and Boss, E. (2003). The beam attenuation to chlorophyll ratio: an optical index of phytoplankton physiology in the surface ocean? Deep Sea Res. I 50 1537-1549. doi: 10.1016/j.dsr.2003.09.002

Behrenfeld, M. J., and Boss, E. (2006). Beam attenuation and chlorophyll concentration as alternative optical indices of phytoplankton biomass. J. Mar. Res. 64, 431-451. doi: 10.1357/002224006778189563

Behrenfeld, M. J., Boss, E., Siegel, D. A., and Shea, D. M. (2005). Carbonbased ocean productivity and phytoplankton physiology from space. Glob. Biogeochem. 19, GB1006. doi: 10.1029/2004GB002299

Behrenfeld, M. J., Hu, Y., Hostetler, C. A., Dall'Olmo, G., Rodier, S. D., Hair, J. W., et al. (2013). Space-based lidar measurements of global ocean carbon stocks. Geophys. Res. Lett. 40, 4355-4360. doi: 10.1002/grl.50816

Behrenfeld, M. J., Marañón, E., Siegel, D. A., and Hooker, S. B. (2002). Photoacclimation and nutrient-based model of light-saturated photosynthesis for quantifying oceanic primary production. Mar. Ecol. Prog. Ser. 228, 103-117. doi: 10.3354/meps228103

Behrenfeld, M. J., O’Malley, R. T., Boss, E. S., Westberry, T. K., Graff, J. R., Halsey, K. H., et al. (2015). Revaluating ocean warming impacts on global phytoplankton. Nat. Clim. Change 6, 323-330. doi: 10.1038/nclimate2838

Bishop, J. K. (1999). Transmissometer measurement of POC. Deep Sea Res. 46, 353-369. doi: 10.1016/S0967-0637(98)00069-7
Newton International Fellowships grant NF150203, and to the Partnership for Observation of the Global Oceans (POGO) for the training support provided by the POGO Visiting Fellowship for training on-board the Atlantic Meridional Transect 24. This study is a contribution to the international IMBER project and was supported by the UK Natural Environment Research Council National Capability funding to Plymouth Marine Laboratory and the National Oceanography Centre, Southampton. This is contribution number 292 of the AMT programme.

Bishop, J. K., Davis, R. E., and Sherman, J. T. (2002). Robotic observations of dust storm enhancement of carbon biomass in the North Pacific. Science 298, 817-821. doi: 10.1126/science. 1074961

Bishop, J. K. B., and Wood, T. J. (2009). Year-round observations of carbon biomass and flux variability in the Southern Ocean. Global Biogeochem. Cycles 23:GB2019. doi: 10.1029/2008GB003206

Bishop, J. K., Wood, T. J., Davis, R. E., and Sherman, J. T. (2004). Robotic observations of enhanced carbon biomass and export at $55 \mathrm{~S}$ during SOFeX. Science 304, 417-420. doi: 10.1126/science.1087717

Boss, E., Guidi, L., Richardson, M. J., Stemmann, L., Gardner, W., Bishop, J. K., et al. (2015). Optical techniques for remote and in-situ characterization of particles pertinent to GEOTRACES. Prog. Oceanogr. 133, 43-54. doi: 10.1016/j.pocean.2014.09.007

Boss, E. S., Collier, R., Pegau, W. S., Larson, G., and Fennel, K. (2007). "Measurements of spectral optical properties and their relation to biogeochemical variables and processes in Crater Lake, Crater Lake National Park, OR," in Long-term Limnological Research and Monitoring at Crater Lake, eds G. L. Larson, R. W. Collier, and M. W. Buktenica (Dordrecht: Springer), 149-159.

Bricaud, A., Babin, M., Morel, A., and Claustre, H. (1995). Variability in the chlorophyll-specific absorption coefficients of natural phytoplankton: analysis and parameterization. J. Geophys. Res. Oceans 100, 13321-13332. doi: 10.1029/95JC00463

Bricaud, A., Morel, A., Babin, M., Allali, K., and Claustre, H. (1998). Variations of light absorption by suspended particles with chlorophyll a concentration in oceanic (case 1) waters: analysis and implications for bio-optical models. $J$. Geophys. Res. Oceans 103, 31033-31044.

Bricaud, A., and Stramski, D. (1990). Spectral absorption coefficients of living phytoplankton and nonalgal biogenous matter: a comparison between the Peru upwelling area and the Sargasso Sea. Limnol. Oceanogr. 35, 562-582.

Briggs, N., Perry, M. J., Cetinić, I., Lee, C., D’Asaro, E., Gray, A. M., et al. (2011). High-resolution observations of aggregate flux during a subpolar North Atlantic spring bloom. Deep Sea Res. Part I 58, 1031-1039. doi: 10.1016/j.dsr.2011.07.007

Campbell, J. W. (1995). The lognormal distribution as a model for bio-optical variability in the sea. J. Geophys. Res. Oceans 100, 13237-13254.

Cetinić, I., Perry, M. J., Briggs, N. T., Kallin, E., D’Asaro, E. A., and Lee, C. M. (2012). Particulate organic carbon and inherent optical properties during 2008 North Atlantic Bloom experiment. J. Geophys. Res. Oceans 117:C06028. doi: 10.1029/2011JC007771

Claustre, H., Morel, A., Babin, M., Cailliau, C., Marie, D., Marty, J. C., et al. (1999). Variability in particle attenuation and chlorophyll fluorescence in the tropical Pacific: scales, patterns, and biogeochemical implications.). J. Geophys. Res. Oceans 104, 3401-3422.

Dall'Olmo, G., Boss, E., Behrenfeld, M. J., and Westberry, T. K. (2012). Particulate optical scattering coefficients along an Atlantic Meridional Transect. Opt. Express 20, 21532-21551. doi: 10.1364/OE.20.021532

Dall'Olmo, G., and Mork, K. A. (2014). Carbon export by small particles in the Norwegian Sea. Geophys. Res. Lett. 41, 2921-2927. doi: 10.1002/2014GL059244

Dall'Olmo, G., Westberry, T. K., Behrenfeld, M. J., Boss, E., and Slade, W. H. (2009). Significant contribution of large particles to optical backscattering in the open ocean. Biogeosciences 6, 947-967. doi: 10.5194/bg-6-947-2009

DuRand, M. D., Green, R. E., Sosik, H. M., and Olson, R. J. H. (2002). Diel variations in optical properties of Micromonas pusilla (Prasinophyceae). J. Phycol. 38, 1132-1142. doi: 10.1046/j.1529-8817.2002.02008.x 
Estapa, M. L., Buesseler, K., Boss, E., and Gerbi, G. (2013). Autonomous, highresolution observations of particle flux in the oligotrophic ocean. Biogeosciences 10, 5517-5531. doi: 10.5194/bg-10-5517-2013

Gardner, W. D., Mishonov, A. V., and Richardson, M. J. (2006). Global POC concentrations from in-situ and satellite data. Deep Sea Res. Part II 53, 718-740. doi: 10.1016/j.dsr2.2006.01.029

Gardner, W. D., Richardson, M. J., Carlson, C. A., Hansell, D., and Mishonov, A. V. (2003). Determining true particulate organic carbon: bottles, pumps and methodologies. Deep Sea Res. Part II 50, 655-674. doi: 10.1016/S0967-0645(02)00589-1

Gardner, W. D., Walsh, I. D., and Richardson, M. J. (1993). Biophysical forcing of particle production and distribution during a spring bloom in the North Atlantic. Deep Sea Res. Part II 40, 171-195. doi: 10.1016/0967-0645(93)9 0012-C

Graff, J. R., Westberry, T. K., Milligan, A. J., Brown, M. B., Dall'Olmo, G., van Dongen-Vogels, V., et al. (2015). Analytical phytoplankton carbon measurements spanning diverse ecosystems. Deep Sea Res. Part I 102, 16-25. doi: 10.1016/j.dsr.2015.04.006

Honjo, S., Manganini, S. J., Krishfield, R. A., and Francois, R. (2008). Particulate organic carbon fluxes to the ocean interior and factors controlling the biological pump: a synthesis of global sediment trap programs since 1983. Prog. Oceanogr. 76, 217-285. doi: 10.1016/j.pocean.2007.11.003

Huot, Y., Morel, A., Twardowski, M. S., Stramski, D., and Reynolds, R. A. (2008). Particle optical backscattering along a chlorophyll gradient in the upper layer of the eastern South Pacific Ocean. Biogeosciences 5, 495-507. doi: 10.5194/bg-5-495-2008

Kirk, J. (1975). A theoretical analysis of the contribution of algal cells to the attenuation of light within natural waters. I. General treatment of suspensions of pigmented cells. New Phytol. 75, 11-20. doi: 10.1111/j.1469-8137.1975.tb01366.x

Knap, A. H., Michaels, A., Close, A. R., Ducklow, H., and Dickson, A. G. (eds.) (1996). Protocols for the Joint Global Ocean Flux Study (JGOFS) core measurements, Manuals IOC Guides 29, United Nation Education Science and Culture Organization (Paris), 170.

Lee, Z. P., Carder, K. L., Peacock, T. G., Davis, C. O., and Mueller, J. L. (1996). Method to derive ocean absorption coefficients from remote-sensing reflectance. Appl. Opt. 35, 453-462. doi: 10.1364/AO.35.000453

Liu, Z., Cochran, J. K., Lee, C., Gasser, B., Miquel, J. C., and Wakeham, S. G. (2009). Further investigations on why POC concentrations differ in samples collected by Niskin bottle and in situ pump. Deep Sea Res. Part II 56, 1558-1567. doi: 10.1016/j.dsr2.2008.12.019

Liu, Z., Stewart, G., Cochran, J. K., Lee, C., Armstrong, R. A., Hirschberg, D. J., et al. (2005). Why do POC concentrations measured using Niskin bottle collections sometimes differ from those using in-situ pumps? Deep Sea Res. Part I 52, 1324-1344. doi: 10.1016/j.dsr.2005.02.005

Loisel, H., and Morel, A. (1998). Light scattering and chlorophyll concentration in case 1 waters: a reexamination. Limnol. Oceanogr. 43, 847-858. doi: 10.4319/lo.1998.43.5.0847

Longhurst, A. R. (1998). Ecological Geography of the Sea. San Diego, CA: Academic Press, 398.

Martinez-Vicente, V., Dall'Olmo, G., Tarran, G., Boss, E., and Sathyendranath, S. (2013). Optical backscattering is correlated with phytoplankton carbon across the Atlantic Ocean. Geophys. Res. Lett. 40, 1154-1158. doi: 10.1002/grl.50252

Menzel, D. W. (1966). Bubbling of sea water and the production of organic particles: a re-evaluation. Deep Sea Res. Oceanogr. Abstr. 13, 963-966. doi: 10.1016/0011-7471(76)90913-X

Menzel, D. W. (1967). Particulate organic carbon in the deep sea. Deep Sea Res. Oceanogr. Abstr. 14, 229-238. doi: 10.1016/0011-7471(67)90008-3

Mishonov, A. V., Gardner, W. D., and Richardson, M. J. (2003). Remote sensing and surface POC concentration in the South Atlantic. Deep Sea Res. Part II 50, 2997-3015. doi: 10.1016/j.dsr2.2003.07.007

Mitchell, C., Cunningham, A., and McKee, D. (2014). Remote sensing of particulate absorption and their biogeochemical interpretation: a case study in the Irish Sea. Remote Sens. Environ. 152, 74-82. doi: 10.1016/j.rse.2014. 06.003

Moran, S. B., Charette, M. A., Pike, S. M., and Wicklund, C. A. (1999). Differences in seawater particulate organic carbon concentration in samples collected using small-and large-volume methods: the importance of DOC adsorption to the filter blank. Mar. Chem. 67, 33-42. doi: 10.1016/S0304-4203(99) 00047-X

Morel, A., and Bricaud, A. (1981). Theoretical results concerning light absorption in a discrete medium, and application to specific absorption of phytoplankton. Deep Sea Res. 28, 1375-1393. doi: 10.1016/0198-0149(81) 90039-X

Morel, A., and Prieur, L. (1977). Analysis of variations in ocean color. Limnol. Oceanogr. 22, 709-722. doi: 10.4319/lo.1977.22. 4.0709

Mueller, J. L., Fargion, G. S., McClain, C. R., Pegau, S., Zanefeld, J. R. V., Mitchell, B. G., et al. (2003). "Ocean optics protocols for satellite ocean color sensor validation, revision 4, volume IV: Inherent optical properties: Instruments, characterizations, field measurements and data analysis protocols," in NASA Tech. Memo. 2003 - 211621/Rev4, Vol. II, eds J. L. Mueller, G. S. Fargion, and C. R. McClain (Greenbelt, MD: NASA GSFC), 56.

Poulton, A. J., Sanders, R., Holligan, P. M., Stinchcombe, M. C., Adey, T. R., Brown, L., et al. (2006). Phytoplankton mineralization in the tropical and subtropical Atlantic Ocean. Global Biogeochem. Cycles 20:GB4002. doi: 10.1029/2006GB 002712

Sarmiento, J. L., and Gruber, N. (2006). Ocean Biogeochemical Dynamics. Princeton, NJ: Princeton University Press

Slade, W. H., Boss, E., Dall'Olmo, G., Langner, M. R., Loftin, J., Behrenfeld, M. J., et al. (2010). Underway and moored methods for improving accuracy in measurement of spectral particulate absorption and attenuation. J. Atmos. Ocean Tech. 27, 1733-1746. doi: 10.1175/2010JTECH O755.1

Smith, R. C., and Baker, K. S. (1978). The bio-optical state of ocean waters and remote sensing. Limnol. Oceanogr. 23, 247-259. doi: 10.4319/lo.1978.23. 2.0247

Stramska, M., and Stramski, D. (2005). Variability of particulate organic carbon concentration in the north polar Atlantic based on ocean color observations with Sea-viewing Wide Field-of-view Sensor (SeaWiFS). J. Geophys. Res. Oceans 110(C10). doi: 10.1029/2004jc002762

Stramski, D., Boss, E., Bogucki, D., and Voss, K. J. (2004a). The role of seawater constituents in light backscattering in the ocean. Prog. Oceanogr. 61, 27-56. doi: 10.1016/j.pocean.2004.07.001

Stramski, D., Reynolds, R. A., Babin, M., Kaczmarek, S., Lewis, M. R., Röttgers, R., et al. (2008). Relationships between the surface concentration of particulate organic carbon and optical properties in the eastern South Pacific and eastern Atlantic Oceans. Biogeosciences 5, 171-201. doi: 10.5194/bg-5171-2008

Stramski, D., Reynolds, R. A., Kahru, M., and Mitchell, B. G. (1999). Estimation of particulate organic carbon in the ocean from satellite remote sensing. Science 285, 239-242. doi: 10.1126/science.285.54 25.239

Stramski, D., Wozniak, S. B., and Flatau, P. J. (2004b). Optical properties of Asian mineral dust suspended in seawater. Limnol. Oceanogr. 49, 749-755. doi: 10.4319/lo.2004.49.3.0749

Tarran, G. A., Heywood, J. L., and Zubkov, M. V. (2006). Latitudinal changes in the standing stocks of nano- and picoeukaryotic phytoplankton in the Atlantic Ocean. Deep Sea Res. Part II 53, 1516-1529. doi: 10.1016/j.dsr2.2006. 05.004

Trüper, H., and Yentsch, C. S. (1967). Use of glass fiber filters for the rapid preparation of in vivo absorption spectra of photosynthetic bacteria. J. Bacteriol. 94, 1255-1256.

Turnewitsch, R., Springer, B. M., Kiriakoulakis, K., Vilas, J. C., Arístegui, J., Wolff, G., et al. (2007). Determination of particulate organic carbon (POC) in seawater: the relative methodological importance of artificial gains and losses in two glass-fiber-filter-based techniques. Mar. Chem. 105, 208-228. doi: 10.1016/j.marchem.2007.01.017

Twardowski, M. S., Claustre, H., Freeman, S. A., Stramski, D., and Huot, Y. (2007). Optical backscattering properties of the "clearest" natural waters. Biogeosciences 4, 1041-1058. doi: 10.5194/bg-4-10 41-2007

Van Heukelem, L., and Thomas, C. S. (2001). Computer-assisted high-performance liquid chromatography method development with applications to the isolation and analysis of phytoplankton pigments. J. Chromatogr. A 910, 31-49. doi: 10.1016/S0378-4347(00)00603-4 
Volk, T., and Hoffert, M. I. (1985). "Ocean Carbon Pumps: Analysis of Relative Strengths and Efficiencies in Ocean-Driven Atmospheric $\mathrm{CO}_{2}$ Changes," in The Carbon Cycle and Atmospheric CO2: Natural Variations Archean to Present, Geophysical Monograph Series, Vol. 32, eds E. T. Sundquist and W. S. Broecker (Washington, DC: AGU), 99-110.

Westberry, T. K., Dall'Olmo, G., Boss, E., Behrenfeld, M. J., and Moutin, T. (2010). Coherence of particulate beam attenuation and backscattering coefficients in diverse open ocean environments. Opt. Express 18, 15419-15425. doi: 10.1364/OE.18.015419

Wozniak, S. B., Meler, J., Lednicka, B., Zdun, A., and Ston-Egiert, J. (2011). Inherent optical properties of suspended particulate matter in the southern Baltic Sea. Oceanologia 53, 691-729. doi: 10.5697/oc. $53-3.691$
Conflict of Interest Statement: The authors declare that the research was conducted in the absence of any commercial or financial relationships that could be construed as a potential conflict of interest.

The reviewer ML and handling Editor declared their shared affiliation

Copyright (c) 2017 Rasse, Dall'Olmo, Graff, Westberry, van Dongen-Vogels and Behrenfeld. This is an open-access article distributed under the terms of the Creative Commons Attribution License (CC BY). The use, distribution or reproduction in other forums is permitted, provided the original author(s) or licensor are credited and that the original publication in this journal is cited, in accordance with accepted academic practice. No use, distribution or reproduction is permitted which does not comply with these terms. 